\title{
Novel lipid nanoparticle provides potent SARS-CoV- 2 mRNA vaccine at low dose with low local reactogenicity, high thermostability and limited systemic biodistribution
}

\section{Suman Alishetty}

George Mason University

Manuel Carrasco

George Mason University

Mohamad-Gabriel Alameh

University of Pennsylvania https://orcid.org/0000-0002-5672-6930

Mikell Paige

George Mason University

Hooda Said

George Mason University

Lacey Wright

George Mason University

Aarthi Narayanan

George Mason University

Farhang Alem

George Mason University

Keziah Hernandez

George Mason University

\section{Patrick Gillevet}

George Mason University

\section{Ousamah Soliman}

University of Pennsylvania

Philip Hicks

University of Pennsylvania

Tomaz Manzoni

University of Pennsylvania

\section{Paul Bates}

University of Pennsylvania

Alisa Stephens-Shields

University of Pennsylvania

https://orcid.org/0000-0001-7734-5566 


\section{Thomas Cleveland}

Institute for Bioscience and Biotechnology Research and National Institute of Standards and Technology

\section{Alexander Grishaev}

National Institute of Standards and Technology

\section{Drew Weissman}

University of Pennsylvania

Michael Buschmann ( $\sim$ mbuschma@gmu.edu )

George Mason University https://orcid.org/0000-0001-7555-8189

\section{Article}

Keywords: mRNA, mRNA vaccines, SARS-CoV-2, lipid nanoparticle, ionizable lipid, MC3

Posted Date: August 17th, 2021

DOI: https://doi.org/10.21203/rs.3.rs-798453/v1

License: (c) (i) This work is licensed under a Creative Commons Attribution 4.0 International License. Read Full License 


\section{Novel lipid nanoparticle provides potent SARS-CoV-2 mRNA vaccine at low dose with low local reactogenicity, high thermostability and limited systemic biodistribution}

Suman Alishetty ${ }^{1}$, Manuel J. Carrasco ${ }^{1}$, Mohamad-Gabriel Alameh ${ }^{2}$, Mikell Paige ${ }^{3}$, Hooda Said ${ }^{1}$, Lacey Wright ${ }^{1}$, Aarthi Narayanan ${ }^{4}$, Farhang Alem ${ }^{5}$, Keziah R Hernandez ${ }^{5}$, Pat Gillevet ${ }^{6}$, Ousamah Soliman $^{2}$, Philip Hicks ${ }^{7}$, Tomaz B. Manzoni ${ }^{7}$, Paul Bates ${ }^{7}$, Alisa J. Stephens-Shields ${ }^{8}$, Thomas E. Cleveland IV ${ }^{9}$, Alexander Grishaev ${ }^{9}$, Drew Weissman ${ }^{10}$, Michael D. Buschmann ${ }^{1 *}$

${ }^{1}$ Department of Bioengineering, George Mason University

4400 University Drive, MS 1J7, Fairfax, VA 22030

${ }^{2}$ Perelman School of Medicine, University of Pennsylvania, 130 Stemmler Hall, 3450 Hamilton Walk, Philadelphia, PA 19104

${ }^{3}$ Department of Chemistry \& Biochemistry, George Mason University 4400 University Drive, Fairfax, VA 22030

${ }^{4}$ Department of Biology, George Mason University

4400 University Drive, Fairfax, VA 22030

${ }^{5}$ National Center for Biodefence and Infectious Diseases, George Mason University 4400 University Drive, Fairfax, VA 22030

${ }^{6}$ Microbiome Analysis Center, Department of Biology, George Mason University 10900 University Blvd, Manassas, VA 20110. 
${ }^{7}$ Perelman School of Medicine, University of Pennsylvania Department of Microbiology 303A Johnson Pavilion, 3610 Hamilton Walk, Philadelphia, PA 19104

${ }^{8}$ Perelman School of Medicine, University of Pennsylvania Department of Biostatistics, Epidemiology and Informatics 423 Guardian Dr, 628 Blockley Hall, Philadelphia, PA 19104

${ }^{9}$ Institute for Bioscience and Biotechnology Research and National Institute of Standards and Technology 9600 Gudelsky Dr., Rockville, MD 20850

${ }^{10}$ Perelman School of Medicine, University of Pennsylvania 410B Hill Pavilion, 380 S. University Ave, Philadelphia, PA 19104

*To whom correspondence should be addressed: Michael Buschmann, mbuschma@gmu.edu, 703$755-5627$ 


\section{Abstract}

Concerns with current mRNA Lipid Nanoparticle (LNP) systems include dose-limiting reactogenicity, adverse events that may be partly due to systemic off target expression of the immunogen, and a very limited understanding of the mechanisms responsible for the frozen storage requirement. We applied a new rational design process to identify a novel multiprotic ionizable lipid, called C24, as the key component of the mRNA LNP delivery system. We show that the resulting C24 LNP has a multistage protonation behavior resulting in greater endosomal protonation and greater translation of an mRNA-encoded luciferase reporter after intramuscular (IM) administration compared to the standard reference MC3 LNP. Off-target expression in liver after IM administration was reduced 6 fold for the C24 LNP compared to MC3. Neutralizing titers in immunogenicity studies delivering a nucleoside-modified mRNA encoding for the diproline stabilized spike protein immunogen were 10 fold higher for the C24 LNP versus MC3, and protection against viral challenge in a SARS-CoV-2 mouse model occurred at a very low $0.25 \mu \mathrm{g}$ prime/boost dose of the same immunogen in the C24 LNP. Injection site inflammation was notably reduced for C24 compared to MC3. In addition, we found the C24 LNP to be entirely stable in bioactivity and mRNA integrity when stored at $4{ }^{\circ} \mathrm{C}$ for at least 19 days. Storage at higher temperatures reduced both bioactivity and mRNA integrity, but less so for $\mathrm{C} 24$ than $\mathrm{MC} 3$, and in a manner consistent with the phosphodiester transesterification reaction mechanism of mRNA cleavage. The higher potency, lower injection site inflammation, and higher stability of the C24 LNP present important advancements in the evolution mRNA vaccine delivery.

Keywords: mRNA, mRNA vaccines, SARS-CoV-2, lipid nanoparticle, ionizable lipid, MC3 


\section{Introduction}

There are 2 completed and 6 ongoing clinical trials for COVID-19 mRNA vaccines ${ }^{1}$. The BioNTech/Pfizer and Moderna products have received Emergency Use Authorization ${ }^{2,3}$ and announced results from phase 3 clinical trials that reported efficacy greater than $94 \%$ for reduction of SARS-CoV-2 symptomatic infection after 2 doses of a nucleoside-modified mRNA encoding the spike protein delivered in a lipid nanoparticle $(\mathrm{LNP})^{4,5}$. Recent interim data from a trial by CureVac contained disappointing results with only $47 \%$ protection $^{6}$, possibly due to the use of non-nucleoside-modified mRNA, which has higher innate immunogenicity than nucleosidemodified $\mathrm{mRNA}^{7}$, and thereby limiting the dose to $12 \mu \mathrm{g}$ in the CureVac trial versus $30 \mu \mathrm{g}$ for BioNTech and $100 \mu \mathrm{g}$ for Moderna. These latter two doses were maximum tolerated doses determined in phase 1 trials where higher doses $\left(250 \mu \mathrm{g}\right.$ Moderna $^{8}, 100 \mu \mathrm{g}$ for BioNTech $\left.{ }^{9}\right)$ were $^{2}$ discontinued due to frequent and severe injection site pain. Data from the clinical trials ${ }^{10,11}$ as well as post-approval follow-up data ${ }^{12,13}$ indicate the Moderna vaccine has a higher frequency of adverse events (ADEs) and reactogenicity than the BioNTech vaccine which could also be related to its higher dose (100 $\mu \mathrm{g}$ Moderna versus $30 \mu \mathrm{g}$ BioNTech/Pfizer). Vaccine reactogenicity is thereby dose-related, generating a narrow successful dose range for mRNA vaccines that motivates the identification of more efficient mRNA delivery systems to achieve protection at lower doses.

In addition to injection site pain that is seen in nearly all subjects, systemic adverse reactions are seen in nearly half, and allergy-type reactions can be found in as many as $2 \%{ }^{12}$ with anaphylactoid reactions in around 1 in $100,000^{14}$. Cases of myocarditis ${ }^{15}$ and thrombocytopenia ${ }^{16}$ have also been identified as potentially mRNA vaccine-related. These ADEs and reactogenicity may be due to innate inflammatory responses to the lipids or mRNA, molecular mimicry between viral spike protein and endogenous proteins ${ }^{15}$, and off-target biodistribution and mRNA expression at unintended sites following intramuscular (IM) injection. For example, IM injection of LNPs containing an mRNA-encoded luciferase in mice showed high levels of liver expression at 6 hours (Fig S4 in ${ }^{17}$ ). The current emergency-approved vaccines also generated off-target distribution and expression in liver and other organs in rodent preclinical models ${ }^{18,19}$. Our recent work showed a means to minimize off-target expression by using a less negatively charged mRNA-LNP that is more locally retained in the injected muscle and draining lymph nodes versus trafficking systemically as seen by expression in liver ${ }^{20}$. A final challenge for current mRNA vaccines is the 
need for frozen storage with relatively short stability times for non-frozen conditions, severely limiting global vaccination. Unfortunately, current literature does not provide any data to illuminate the mechanisms involved in loss of mRNA-LNP bioactivity ${ }^{21,22}$ during storage although regulatory documentation suggests a loss of mRNA integrity is involved ${ }^{18,19}$. In order to widely implement mRNA-LNP vaccines for infectious diseases in the future, there is an urgent need to increase their potency and reduce dose, as well as to control biodistribution and increase understanding of the mechanisms determining stability during storage.

The design of the ionizable lipid in LNPs is considered the key aspect that determines potency or mRNA delivery efficiency, as well as degradability, toxicity, reactogenicity and the adjuvant properties of the LNP ${ }^{23}$. Early studies using siRNA containing LNPs showed that only 1-2\% percent of the siRNA in endosomes is released from the LNP and from endosomes and loads into the RNA-induced silencing complex ${ }^{24}$. The current LNPs in COVID-19 vaccines may increase endosomal release several fold ${ }^{25,26}$ but still release only a small fraction of mRNA for cytosolic translation. For this reason, the main design principle guiding improvements to ionizable lipids is to increase endosomal release that occurs due to protonation of the ionizable lipid in the endosome followed by ion pairing with a negatively charged endogenous endosomal phospholipid where this ion pair can open the endosomal membrane to release mRNA into the cytoplasm ${ }^{27}$. The endosomal protonation requirement is well established and is summarized as requiring the pKa of the LNP to be in the 6-7 range $^{28}$. We recently showed that this LNP pKa is different from the ionizable lipid $\mathrm{pKa}$ that is in the 8-10 range ${ }^{20}$ and this $2-3$ point difference as mainly due to proton partitioning between the lipid phase and the aqueous media external to the LNP. This insight has now permitted us in the current study to systematically scan and screen theoretical structures of novel multiprotic head groups of ionizable lipids, since we are able to predict the pKa of the resulting LNP based on the structure of the ionizable lipid.

In addition to endosomal protonation, another principle of ionizable lipid design is the molecular shape hypothesis ${ }^{29,30}$, which states that the lipid tails should have a wider cross-section than the head group, thereby creating a cone-shaped ion pair with an endogenous phospholipid that is not compatible with a lipid bilayer and therefore destabilizes it for endosomal release. The evolution of ionizable lipids displays an increased level of lipid tail branching that augments a cone-shaped morphology. MC3, the standard reference ionizable lipid in the approved Onpattro silencing RNA 
product from Alnylam has a dilinoleic tail, the Moderna SM-102 ionizable lipid has 3 saturated alkyl branches and the Acuitas ALC 0315 in the BioNTech/Pfizer product has 4 saturated alkyl $\operatorname{tails}^{23}$. A third critical component of the ionizable lipid is the linker between the head group and tails that should be degradable in order to permit elimination in the body and limit accumulation ${ }^{31}$. A favored linker in this respect is a primary ester since it has been shown to degrade quickly in vivo to minimize accumulation and allow repeat administration ${ }^{31}$. This rapid degradability was associated with reduced inflammation at the IM injection site and increased tolerability ${ }^{26}$.

We designed a new ionizable lipid for mRNA-LNP vaccines based on the above criteria. We theoretically screened a broad molecular design space of head groups that were not limited to monoprotic units used in current mRNA LNP vaccines. The incorporation of more than one ionizable nitrogen in the head group can provide an additional dimension to both enhance endosomal protonation and to control charge of the LNP that influences biodistribution. The chosen trivalent head group, 4-methyl-1-piperazinebutanamine, was linked via two degradable primary esters to octyldodecyl tails creating 4 saturated alkyl tails with non-symmetric 8 and 10 carbon lengths. The resulting compound, abbreviated C24, was used along with the standard 3 additional lipids to produce mRNA-LNPs containing a nucleoside-modified mRNA that encoded for either a luciferase reporter or a diproline-stabilized membrane-bound spike protein (S2P) immunogen from SARS-CoV-2 that is equivalent to the immunogen in the current emergency authorized mRNA vaccines. We comprehensively studied the physicochemical properties of the C24 ionizable lipid, the resulting C24 LNP, as well as immunogenicity, protection against lethal SARS-CoV-2 challenge, injection site inflammation and stability of C24 mRNA-LNPs and mRNA integrity during liquid storage. By direct comparison to the standard MC3 LNP, which was used in the first two phase 1 clinical trials of nucleoside-modified mRNA for influenza ${ }^{32}$, the C24 mRNA LNP appears significantly more potent with 10 fold higher neutralizing antibody titers than MC3, protecting against SARS-CoV-2 infection at a low $0.25 \mu \mathrm{g}$ dose administered twice in mice and is less inflammatory at the injection site while entirely maintaining bioactivity beyond 2 weeks when stored in a liquid format at $4^{\circ} \mathrm{C}$.

\section{Results and Discussion}

Trivalent head group of C24 ionizable lipid displays molecular and LNP ionization properties that augment protonation in the endosomal $\mathrm{pH}$ range 
The initial screening of our ionizable lipid design space included more than 100 head groups, 10 linkers and 50 alkyl tails that combine for over 50,000 potential ionizable lipid candidates. We calculated aqueous phase pKas for $\sim 500$ candidates that sampled this design space and selected several head groups for synthesis with acrylate bearing alkyl tails using a synthetic procedure that involved only 2 reactions and one catalyst versus more than 5 reactions and 7 catalysts for the ionizable lipids in the current COVID-19 mRNA vaccines ${ }^{26,33}$. The simplicity of the reaction scheme resulted in much fewer purification steps, much shorter synthetic time, and over $80 \%$ yield producing an estimated 10 fold reduction in cost that could faciliate global vaccination campaigns. More than 30 candidate ionizable lipids were initially synthesized and characterized physicochemically and for certain biological performance indicators resulting in the selection of C24 (Fig 1a) for further investigation in the current study. C24 bears a trivalent 4-methyl-1piperazinebutanamine head group with theoretical aqueous phase pKas ranging from 4 to 8 , two of which were close in predicted values (7.7 and 7.8). We synthesized a water soluble analogue (C24-WSA) and measured the pKa of each nitrogen using an established ${ }^{1} \mathrm{H}$ NMR method ${ }^{20}$ confirming theoretical pKas to within 0.4 units (Fig 1b). A slightly stretched deviation from an ideal Henderson-Hasselbalch behavior was observed for the terminal nitrogen (pKa 8.1, red in Fig 1b) consistent with an interaction with the nitrogen atom with a slightly lower pKa (7.5 in Fig 1b) that protonates almost simultaneously. This observation also indicates the potential for proton coordination between these two sites and the formation of a dative bond during initial protonation stages. NMR analyses of the water soluble MC3 analogue revealed a pKa of 9.5 (Fig 1c) that is very similar to the predicted value of 9.4 (Fig 1a). Protonation of LNPs made with C24 and MC3 was assessed using the TNS dye-binding assay that measures surface charge and with zeta potential by electrophoretic mobility that measures net charge of the LNP, as we described recently ${ }^{20}$. The TNS dye-binding assay revealed a higher $\mathrm{pKa}$ for $\mathrm{C} 24$ (6.77) than $\mathrm{MC} 3$ (6.55) and a larger increase in surface protonation when $\mathrm{pH}$ drops from 7.4 to 6 (4517 versus 2559 RFU in Fig 1f) indicating greater surface protonation in the endosomal $\mathrm{pH}$ range for $\mathrm{C} 24$ versus $\mathrm{MC} 3$. The lower $\mathrm{pH}$ limit in calculating endosomal protonation was taken as 6 for the TNS dye-binding assay since there is no change in surface charge below this $\mathrm{pH}$. Electrophoretic mobility measurements, in contrast to the TNS dye-binding assay, measure net charge of the LNP and show broader changes in LNP net charge reflected by zeta potential increasing down to $\mathrm{pH} 3$ (Fig 1e). MC3 followed very closely the behavior of the extended Henderson-Hasselbalch model originally proposed for 
polyelectrolytes ${ }^{34}$ since it accounts for ionization-state-dependent $\mathrm{pKa}$ of closely interacting ionizable sites such as the thousands of dimethylamine MC3 head groups that are in close proximity within the LNP. The extended Henderson-Hasselbalch analyses revealed a zeta potential pKa of 5.33 and a pI of 5.57 for the MC3 LNP (Fig 1f). The ionization behavior of the C24 LNP was more complex where a rapidly rising zeta potential occurred from $\mathrm{pH} 7.4$ to $\mathrm{pH} 6$ corresponding to simultaneous protonation of 2 of the 3 nitrogens in the head group with aqueous phase pKas of 8.1 and 7.5 (Fig 1b) below which the zeta potential continued to rise with the contribution of the central nitrogen with a pKa of 3.7 (Fig 1b). This multiprotic ionization behavior for C24 was not well represented by the extended Henderson-Hasselbalch model (dashed versus solid red line in Fig 1e) that resulted in a zeta potential pKa of 5.21 and pI of 6.12 (Fig 1f). The calculation of zeta potential increase from $\mathrm{pH} 7.4$ to $\mathrm{pH} 4.5$ where endosomes are considered to fuse with lysosomes was higher for the C24 LNP than MC3 LNP (25.1 mV versus $14.3 \mathrm{mV}$ in Fig 1f) again indicating a greater level of protonation of $\mathrm{C} 24$ versus $\mathrm{MC} 3$ in the endosomal $\mathrm{pH}$ range. Taken together, the above analyses relate molecular protonation events on monoprotic versus multiprotic head groups to their protonation in the condensed LNP environment and demonstrates an approximately 2 fold increase in protonation of the C24 LNP versus MC 3 in the endosomal pH range.

Size characterization showed C24 LNPs to be slightly larger than MC3 (80 nm versus $64 \mathrm{~nm}$ diameter in Fig 2a) and to have a slightly lower fraction of mRNA that is inaccessible to ribogreen dye-binding ( $68 \%$ versus $79 \%$ in Fig $2 \mathrm{~b}$ ). The fraction of mRNA that is inaccessible to ribogreen is often called encapsulation efficiency, however it is now known that the accessible portion is not a free fraction of mRNA since it may not migrate on a gel-based assay ${ }^{35}$. We used our recently published molecular volume model ${ }^{20}$ of the LNP to estimate the number of copies of the Firefly Luciferase (FLuc) encoding mRNA in each LNP finding 4.5 copies in the MC3 LNP and 6 for the C24 LNP (Fig 2c), on average, due to its larger size. CyroTEM analyses revealed a larger size for the C24 LNP consistent with DLS measurements and both LNPs had a similar structure showing a peripheral bilayer ${ }^{36}$ and an internal electron dense amorphous core (Fig 2d,e).

\section{Luciferase expression of C24 LNP is 4 fold higher than the MC3 LNP upon intramuscular injection and displays 6 fold less off-target expression in liver than MC3}


In vivo expression of the mRNA FLuc encoding reporter after intramuscular (IM) administration of the LNPs in mice at a relatively high dose of $5 \mu \mathrm{g}$ mRNA showed 2 fold higher expression at the injection site for C24 at 4hrs and 24hrs (Figs 3a and 3b). Systemic biodistribution and offtarget expression in liver was high for MC3 (Figs 3). In contrast, C24 at this high dose virtually eliminated systemic biodistribution with a 6 fold reduction of off-target expression in liver compared to MC3 (Fig 3C), an important finding since systemic reactogenicity and adverse events associated with mRNA-LNP vaccines may be linked to systemic biodistribution and off-target expression in sites other than the injection site and draining lymph nodes. The high off-target expression seen here for MC3 is consistent with previous findings for $\mathrm{MC}^{17}$ and regulatory documentation $^{18,19}$ suggest it also occurs in rodent models for the current emergency authorized COVID-19 mRNA vaccines. The mechanism that significantly limits systemic biodistribution for the C24 LNP could be related to its rapid increase in surface charge and net charge near neutral $\mathrm{pH}$ (Fig 1d and 1e), since we found previously that a less negatively charged LNP was more locally contained upon IM adminsitration ${ }^{20}$. IM administration of Fluc-encoding mRNA-LNPs at a lower $0.5 \mu \mathrm{g}$ dose that is more representative of vaccination doses in mice showed C24 to express 4 fold higher than MC3 at the injection site (Fig 3d and 3e). Off target expression could not be detected by IVIS at this 10 fold lower dose due to low signal to noise at the liver site. Daily imaging of mice showed an initial burst of expression lasting 48 hours with a gradual decline to baseline over 5 days (Fig 3f).

\section{Immunogenicity towards mRNA-encoded SARS-CoV-2 spike protein shows higher binding titers and 10 fold higher pseudoneutralization titers for C24 LNP versus MC3 LNP against the original Wuhan strain and against two prominent variants}

LNPs were assembled with nucleoside-modified mRNA encoding for the diproline-stabilized membrane-bound spike protein immunogen (S2P) that is in the current emergency-authorized COVID-19 mRNA vaccines. We performed immunogenicity studies in Balb/c mice by IM administration of two immunizations with dose ranging from $0.1 \mu \mathrm{g}$ to $1 \mu \mathrm{g}$ with 3 weeks between prime and boost and serum analyses for binding antibodies to the receptor-binding domain of the spike protein, as well as neutralization assays to a SARS-CoV-2 pseudovirus. Optical density of the ELISA binding assay at transitional dilutions showed binding antibodies were significantly higher for the C24 LNP versus MC3 at all doses (Fig 4a and 4b). Neutralization assays to a SARS- 
CoV-2 pseudovirus showed C24 LNPs with significant $\sim 10$ fold increases of neutralization titers versus MC3 at all doses after the boost (Fig 4C). A very similar assay done in Balb/c mice with an identical mRNA-encoded immunogen (other mRNA structures differed) in the SM-102 LNP of Moderna revealed titers similar to those of MC3 $(1,000 \text { at } 1 \mu \mathrm{g})^{37}$ suggesting that the C24 LNP may also be more potent than the SM-102 LNP. The $1 \mu \mathrm{g}$ dose delivered in the C24 LNP was also capable of inducing neutralization after a single dose where MC3 did not produce neutralization (Prime in Fig 4c). Finally, we found that serum from animals vaccinated with the highest $1 \mu \mathrm{g}$ dose were capable of neutralizing two variants of SARS-CoV-2 and that titers of C24 were higher than those of MC3 for the tested variants (Fig 4d).

\section{Lethal challenge in the K18-hACE2 mouse reveals complete protection for the C24 LNP at a low, $0.25 \mu \mathrm{g}$, prime/boost dose of nucleoside-modified S2P mRNA and complete elimination of lung infection at $0.5 \mu \mathrm{g}$ dose}

Protection against lethal infection with SARS-CoV-2 after vaccination with mRNA-LNPs containing the S2P immunogen was investigated in the K18-hACE2 transgenic mouse bearing the human ACE2 receptor. C24 and MC3 LNPs containing the S2P immunogen were administered twice at mRNA dose levels ranging from 0.1 to $1 \mu \mathrm{g}$, each with a group of 5 animals, and then challenged with a lethal intranasal dose of the Italian strain (Isolate Italy-INMI1) of SARS-CoV2. Two of the five animals in each group were sacrificed on day 5 to assess viral titers in the lung and the remaining 3 followed until euthanasia criteria were met. We found C24 mRNA LNPs completely protected mice at $0.25 \mu \mathrm{g}$ with one of 3 animals at $0.1 \mu \mathrm{g}$ dose also surviving versus MC3 where protection occurred at $0.5 \mu \mathrm{g}$ dose (Fig 5a). Neutralization titers in a plaque assay showed C24 LNPs achieved titers at $0.25 \mu \mathrm{g}$ that were equivalent to those of MC3 at $1 \mu \mathrm{g}$ dose after both the prime and the boost (Fig $5 \mathrm{~b}$ and c). Lung viral titers examined 5 days after infection found C24 mRNA LNPs entirely blocked lung infection at $0.5 \mu \mathrm{g}$ dose and that MC 3 did not block infection entirely even at the highest $1 \mu \mathrm{g}$ dose. Taken together, these results indicate that C24 LNPs achieve protection against infection at a dose $4 \mathrm{X}$ lower than MC3. The $0.25 \mu \mathrm{g}$ protective dose applied twice in our study is $60 \mathrm{X}$ lower than the single effective dose $(15 \mu \mathrm{g})$ found in an $\mathrm{LNP}^{38}$ containing a self-replicating mRNA for the spike protein and 10X lower than another single dose found with a different $\mathrm{LNP}^{39}$ also containing a self-replicating mRNA. Although these latter studies with self-replicating mRNA are single dose, the required dose is much greater and at a 
level that would be expected to generate unacceptable reactogenicity in humans. The study that is most similar to ours is prime/boost nucleoside modified approach using the S2P immunogen in the SM-102 LNP of Moderna ${ }^{37}$ where doses as high as $1 \mu \mathrm{g}$ of the S2P immunogen in the SM-102 LNP were not capable of blocking lung infection, although they did reduce lung infection compared to PBS controls. The potency of the SM-102 LNP for blocking lung infection in mice therefore appears similar to that of MC3 in our study supporting with the similar potency we found for SM-102 and MC3 neutralization titers against a SARS-CoV-2 pseudovirus (both at $\sim 1,000$ Fig 4c). Taken together these results suggest the C24 LNP system exceeds the potency of MC3 and of SM-102 LNP in mice models. Often, translation to non-human primates and humans is not predictable from mouse models ${ }^{40}$ so that results in larger animal models and clinical studies are required to further assess C24 mRNA LNP vaccines.

\section{Injection site inflammation for the C24 LNP is milder than for the MC3 LNP}

Injection site inflammation for MC3 mRNA LNPs was visually evident $24 \mathrm{hrs}$ post IM administration by macroscopic swelling and a high level of stiffness of the injected leg. Injection site inflammation of C24 mRNA LNPs injected at a $5 \mu \mathrm{g}$ dose was macroscopically lower than the swelling of MC3 LNP injected sites. We therefore fixed and processed the injected legs for standard histological analyses (Paraffin and H\&E staining). We found that the injected $50 \mu \mathrm{L}$ depot of mRNA LNPs was not inside the muscle tissue but was rather deposited mainly in the facial plane between the medial and lateral gastrocnemius (IS in Fig 6a,d,g) and was difficult to distinguish from adipose tissue at these sites. This non-intramuscular site for the LNP depot was due to the standard $3 \mathrm{~mm}$ injection depth passing through the medial gastrocnemius that is $\sim 2 \mathrm{~mm}$ thick. The volume of the medial gastrocnemius is only $\sim 150 \mu \mathrm{L}^{41}$ so that the standard $50 \mu \mathrm{L}$ LNP volume would not likely be contained inside the muscle even if the injection depth were reduced. In comparing $\mathrm{C} 24$ histology to $\mathrm{MC} 3$ we observed greater levels of inflammation for MC3, for example in the synovium which was multicellular and thickened for MC3 versus a normal appearance for $\mathrm{C} 24$ (Fig 6 e,f versus b,c). In addition to infiltration of leukocytes and vasculature at the injected site, we observed the presence of mixed cell-type lymphoid structures (Fig 6 a,g,i) at $24 \mathrm{hrs}$ post administration for both C24 and MC3 LNPs that were absent in control uninjected legs. These rapidly forming (in $24 \mathrm{hrs)} \mathrm{lymphoid} \mathrm{structures} \mathrm{may} \mathrm{play} \mathrm{an} \mathrm{important} \mathrm{role} \mathrm{in} \mathrm{the}$ immune response in mice and are being further characterized. 
Storage of LNPs at $4^{\circ} \mathrm{C}$ reveal C24 LNPs are stable for at least 19 days while storage at higher temperatures induces loss of bioactivity and mRNA cleavage that is consistent with the phosphodiester transesterification reaction mechanism of mRNA cleavage

mRNA LNPs generally require frozen storage and can be stored at refrigerated temperatures for up to 30 days according to instructions for use of the emergency authorized LNPs. Recent reviews $^{21,22}$ have highlighted a nearly total lack of information on mechanisms contributing to instability during storage of mRNA LNPs although European regulatory documentation ${ }^{18,19}$ states that instability is temperature-dependent and involves a loss of mRNA integrity as well as changes in LNP size and generation of impurities. We therefore stored C24 and MC3 FLuc mRNA LNPs for 2 weeks at one of 2 temperatures, $4^{\circ} \mathrm{C}$ or room temperature $\left(\mathrm{RT} \approx 22^{\circ} \mathrm{C}\right)$ in PBS and tested bioactivity by Luciferase expression in vitro. We found that bioactivity was stable (to within the high variability of this bioactivity assay performed on cells seeded on different days) for both $\mathrm{C} 24$ and MC3 LNPs for 2 weeks when stored at $4^{\circ} \mathrm{C}$ but declined by $20-40 \%$ when stored at room temperature (Fig 7a). We did not find any change in LNP size or accessibility to Ribogreen for either storage temperature over 2 weeks (Fig $7 \mathrm{~b}, \mathrm{c}$ ). We calculated the loss of mRNA integrity of the 2,061 nucleotide long FLuc over time using a model derived from data characterizing the temperature- and $\mathrm{pH}$-dependence of the base-catalyzed phosphodiester transesterification and cleavage of mRNA backbone ( $\mathrm{Eq}$ e from ${ }^{42}$ ). The model predicted half-lives of 2,300 days at $4{ }^{\circ} \mathrm{C}$ and 125 days at $22^{\circ} \mathrm{C}$ (RT) and 11 days at $37^{\circ} \mathrm{C}$, all at pH 7.4 (Fig 7d). mRNA backbone cleavage is thereby expected to be exquisitely sensitive to temperature and these trends are qualitatively consistent with previous findings for free mRNA (Fig E2 from ${ }^{43}$ and Fig 2 from $^{44}$ ). We then stored additional mRNA LNPs in PBS at $4{ }^{\circ} \mathrm{C}$ and at $22^{\circ} \mathrm{C}(\mathrm{RT})$ as well as at $37^{\circ} \mathrm{C}$ to accelerate degradation and extracted mRNA in chloroform/methanol to analyze mRNA integrity on a microfluidic electrophoresis device. We found mRNA integrity to be maintained for at least 19 days when stored at $4^{\circ} \mathrm{C}$ while the higher temperatures could produce mRNA cleavage (Fig 7e). mRNA integrity was estimated by the area under the curve (AUC) corresponding to the FLuc mRNA peak normalized to the day 0 value of $\mathrm{C} 24$ and MC3 LNPs taken together. The C24 LNP appeared to maintain higher levels of mRNA integrity than the MC3 LNP at the higher temperatures although sample numbers were too low to permit statistical analyses (Fig 7f). Increased mRNA cleavage at higher temperatures is consistent with the model of based-mediated 
phosphodiester transesterification reaction mechanism of mRNA cleavage ${ }^{42}$ (Fig 7d) but may exhibit a dependence on the LNP environment and on the specific structure of the ionizable lipid in the LNP. The LNP environment may for example accelerate mRNA degradation by the proton partitioning phenomena we found to be responsible for the difference in $\mathrm{pKa}$ of the ionizable lipid in aqueous media versus in the LNP. Namely, the higher proton solvation energy in the lipid environment will exclude protons and raise the $\mathrm{pH}$ in the LNP compared to the external aqueous phase and could thereby accelerate base-mediated mRNA cleavage as predicted by the $\mathrm{pH}$ dependence of the model of base-catalyzed phosphodiester transesterification and cleavage of the mRNA backbone ${ }^{42}$.

\section{Conclusions}

Through a rational design process that includes a theoretical ionization assessment of ionizable lipid candidates, followed by structural considerations that include high levels of branching alkyl tails and quickly degradable primary esters, we identified and synthesized a new ionizable lipid, C24, with a multiprotic trivalent head group. The ionization behavior of the C24 LNP was consistent with molecular ionization characteristics reflecting the multiple protonation stages of the multivalent head group, resulting in an overall doubling of protonation in the endosomal $\mathrm{pH}$ range compared to the MC3 reference mRNA LNP. Intramuscular administration in mouse models showed that mRNA translation was 4 fold higher for $\mathrm{C} 24$ versus $\mathrm{MC} 3$ and this translated to 10 fold higher neutralizing titers in immunogenicity studies and a significantly greater protective capacity in a SARS-CoV-2 challenge model with protection at a low $0.25 \mu \mathrm{g}$ prime/boost dose in mice. Additional important observations for $\mathrm{C} 24$ were a 6 fold lower level of systemic biodistribution compared to MC3 and lower levels of inflammation at the injected site indicating the potential for lower reactogenicity and a wider therapeutic window if these results translate to larger animal models and to human studies. Finally, we found the C24 LNP to maintain bioactivity and mRNA integrity for at least 19 days. When stored at higher temperatures our data suggests base-mediated mRNA cleavage is likely responsible for loss of mRNA integrity and bioactivity in LNPs. The important improvements in potency, reactogenicity and storage properties of the C24 LNP motivate further preclinical studies for eventual use in human mRNA vaccine studies. 


\section{References}

1. Zimmer, C., Corum, J. \& Wee, S.-L. Coronavirus Vaccine Tracker. The New York Times (2021).

2. Pfizer-BioNTech Covid-19 Vaccine FDA EAU Letter of Authorization. https://www.fda.gov/media/144412/download.

3. Moderna COVID-19 Vaccine EUA Letter of Authorization.

https://www.fda.gov/media/144636/download\#: :text=that\%20the\%20Food\%20and\%20Drug,of\%2 0this\%20letter\%2C\%20pursuant\%20to.

4. Polack, F. P. et al. Safety and Efficacy of the BNT162b2 mRNA Covid-19 Vaccine. N. Engl. J. Med. 0, null (2020).

5. Baden, L. R. et al. Efficacy and Safety of the mRNA-1273 SARS-CoV-2 Vaccine. N. Engl. J. Med. 0, null (2020).

6. CureVac Provides Update on Phase 2b/3 Trial of First-Generation COVID-19 Vaccine Candidate, CVnCoV. CureVac https://www.curevac.com/en/2021/06/16/curevac-provides-update-on-phase2b-3-trial-of-first-generation-covid-19-vaccine-candidate-cvncov/ (2021).

7. Karikó, K., Buckstein, M., Ni, H. \& Weissman, D. Suppression of RNA Recognition by Toll-like Receptors: The Impact of Nucleoside Modification and the Evolutionary Origin of RNA. Immunity 23, 165-175 (2005).

8. Jackson, L. A. et al. An mRNA Vaccine against SARS-CoV-2 - Preliminary Report. N. Engl. J. Med. 383, 1920-1931 (2020).

9. Mulligan, M. J. et al. Phase I/II study of COVID-19 RNA vaccine BNT162b1 in adults. Nature 586, 589-593 (2020).

10. Pfizer-BioNTech. FDA Briefing Document for Vaccines and Related Biological Products Advisory Committee Meeting December 10, 2020. https://www.fda.gov/media/144245/download.

11. FDA Briefing Document Moderna Covid-19 Vaccine. https://www.fda.gov/media/144434/download. 
12. Blumenthal, K. G. et al. Acute Allergic Reactions to mRNA COVID-19 Vaccines. JAMA 325, 1562-1565 (2021).

13. Chapin-Bardales, J., Gee, J. \& Myers, T. Reactogenicity Following Receipt of mRNA-Based COVID-19 Vaccines. JAMA 325, 2201-2202 (2021).

14. Shimabukuro, T. T., Cole, M. \& Su, J. R. Reports of Anaphylaxis After Receipt of mRNA COVID-19 Vaccines in the US-December 14, 2020-January 18, 2021. JAMA 325, 1101 (2021).

15. Larson, K. F. et al. Myocarditis after BNT162b2 and mRNA-1273 Vaccination. Circulation CIRCULATIONAHA.121.055913 (2021) doi:10.1161/CIRCULATIONAHA.121.055913.

16. Kuter, D. J. Exacerbation of immune thrombocytopenia following Covid-19 vaccination. Br. J. Haematol. n/a,.

17. Bahl, K. et al. Preclinical and Clinical Demonstration of Immunogenicity by mRNA Vaccines against H10N8 and H7N9 Influenza Viruses. Mol. Ther. 25, 1316-1327 (2017).

18. EMA, 2020a. Assessment report Comirnaty Common name: COVID-19 mRNA vaccine (nucleosidemodified) [WWW Document]. accessed 3.14.21. https://www.ema.eu ropa.eu/en/documents/assessment-report/comirnaty-epar-public-assessment-repo rt_en.pdf.

19. EMA, 2020b. Assessment report COVID-19 Vaccine Moderna Common name: COVID-19 mRNA Vaccine (nucleoside-modified) [WWW Document]. Accessed 3.14.21. https://www.ema.europa.eu/en/documents/assessment-report/covid-19-vaccine-moderna-eparpublic-assessment-report_en.pdf.

20. Carrasco, M. et al. Ionization and Structural Properties of mRNA Lipid Nanoparticles that Influence Expression in Intramuscular and Intravascular Administration. Commun. Biol. Nat. Accepted, (2021).

21. Crommelin, D. J. A., Anchordoquy, T. J., Volkin, D. B., Jiskoot, W. \& Mastrobattista, E. Addressing the Cold Reality of mRNA Vaccine Stability. J. Pharm. Sci. 110, 997-1001 (2021). 
22. Schoenmaker, L. et al. mRNA-lipid nanoparticle COVID-19 vaccines: Structure and stability. Int. J. Pharm. 601, 120586 (2021).

23. Buschmann, M. D. et al. Nanomaterial Delivery Systems for mRNA Vaccines. Vaccines 30 (2021) doi:10.3390/vaccines9010065.

24. Gilleron, J. et al. Image-based analysis of lipid nanoparticle-mediated siRNA delivery, intracellular trafficking and endosomal escape. Nat. Biotechnol. 31, 638-646 (2013).

25. Sabnis, S. et al. A Novel Amino Lipid Series for mRNA Delivery: Improved Endosomal Escape and Sustained Pharmacology and Safety in Non-human Primates. Mol. Ther. 26, 1509-1519 (2018).

26. Hassett, K. J. et al. Optimization of Lipid Nanoparticles for Intramuscular Administration of mRNA Vaccines. Mol. Ther. - Nucleic Acids 15, 1-11 (2019).

27. Cullis, P. R. \& Hope, M. J. Lipid Nanoparticle Systems for Enabling Gene Therapies. Mol. Ther. 25, 1467-1475 (2017).

28. Jayaraman, M. et al. Maximizing the potency of siRNA lipid nanoparticles for hepatic gene silencing in vivo. Angew. Chem. Int. Ed Engl. 51, 8529-8533 (2012).

29. Witzigmann, D. et al. Lipid nanoparticle technology for therapeutic gene regulation in the liver. Adv. Drug Deliv. Rev. (2020) doi:10.1016/j.addr.2020.06.026.

30. Gruner, S. M., Cullis, P. R., Hope, M. J. \& Tilcock, C. P. S. Lipid Polymorphism:The Molecular Basis of Nonbilayer Phases. Annu. Rev. Biophys. Biophys. Chem. 14, 211-238 (1985).

31. Maier, M. A. et al. Biodegradable Lipids Enabling Rapidly Eliminated Lipid Nanoparticles for Systemic Delivery of RNAi Therapeutics. Mol. Ther. 21, 1570-1578 (2013).

32. Feldman, R. A. et al. mRNA vaccines against H10N8 and H7N9 influenza viruses of pandemic potential are immunogenic and well tolerated in healthy adults in phase 1 randomized clinical trials. Vaccine 37, 3326-3334 (2019). 
33. Ansell, S. M. \& Du, X. Novel lipids and lipid nanoparticle formulations for delivery of nucleic acids. (2017).

34. Katchalsky, A. \& Spitnik, P. Potentiometric titrations of polymethacrylic acid. J. Polym. Sci. 2, 432446 (1947).

35. Nogueira, S. S. et al. Polysarcosine-Functionalized Lipid Nanoparticles for Therapeutic mRNA Delivery. ACS Appl. Nano Mater. 3, 10634-10645 (2020).

36. Yanez Arteta, M. et al. Successful reprogramming of cellular protein production through mRNA delivered by functionalized lipid nanoparticles. Proc. Natl. Acad. Sci. 115, E3351-E3360 (2018).

37. Corbett, K. S. et al. SARS-CoV-2 mRNA vaccine design enabled by prototype pathogen preparedness. Nature 586, 567-571 (2020).

38. Huang, Q. et al. A single-dose mRNA vaccine provides a long-term protection for hACE2 transgenic mice from SARS-CoV-2. Nat. Commun. 12, 776 (2021).

39. de Alwis, R. et al. A single dose of self-transcribing and replicating RNA-based SARS-CoV-2 vaccine produces protective adaptive immunity in mice. Mol. Ther. 29, 1970-1983 (2021).

40. Hassett, K. J. et al. Impact of lipid nanoparticle size on mRNA vaccine immunogenicity. J. Controlled Release (2021) doi:10.1016/j.jconrel.2021.05.021.

41. Pratt, S. J. P. \& Lovering, R. M. A stepwise procedure to test contractility and susceptibility to injury for the rodent quadriceps muscle. J. Biol. Methods 1, e8 (2014).

42. Li, Y. \& Breaker, R. R. Kinetics of RNA Degradation by Specific Base Catalysis of Transesterification Involving the 2'-Hydroxyl Group. J. Am. Chem. Soc. 121, 5364-5372 (1999).

43. Roesler, E. et al. Immunize and disappear-Safety-optimized mRNA vaccination with a panel of 29 allergens. J. Allergy Clin. Immunol. 124, 1070-1077.e11 (2009).

44. Jones, K. L., Drane, D. \& Gowans, E. J. Long-term storage of DNA-free RNA for use in vaccine studies. BioTechniques 43, 675-681 (2007). 
45. Baiersdörfer, M. et al. A Facile Method for the Removal of dsRNA Contaminant from In VitroTranscribed mRNA. Mol. Ther. - Nucleic Acids 15, 26-35 (2019).

46. Hensbergen, J. A. van, Gaines, T. W., Wagener, K. B., Burford, R. P. \& Lowe, A. B. Functional $\alpha, \omega-$ dienes via thiol-Michael chemistry: synthesis, oxidative protection, acyclic diene metathesis (ADMET) polymerization and radical thiol-ene modification. Polym. Chem. 5, 6225-6235 (2014).

47. Sartoru, M. et al. New dimethylamino-alkanoyloxy-bis-((tetradec-9-enoyloxy)methyl)propyl tetradec-9-enoate derivative useful in composition for introducing nucleic acid e.g. small interfering RNA for treating disease e.g. anemia, psoriasis, and lung cancer. (2019).

48. Liang, X. et al. Design and Synthesis of Lipidic Organoalkoxysilanes for the Self-Assembly of Liposomal Nanohybrid Cerasomes with Controlled Drug Release Properties. Chem. - Eur. J. 19, 16113-16121 (2013).

49. Sedic, M. et al. Safety Evaluation of Lipid Nanoparticle-Formulated Modified mRNA in the SpragueDawley Rat and Cynomolgus Monkey. Vet. Pathol. 55, 341-354 (2018).

50. Niebel, Y., Buschmann, M. D., Lavertu, M. \& De Crescenzo, G. Combined Analysis of Polycation/ODN Polyplexes by Analytical Ultracentrifugation and Dynamic Light Scattering Reveals their Size, Refractive Index Increment, Stoichiometry, Porosity, and Molecular Weight. Biomacromolecules 15, 940-947 (2014).

51. Filion, D., Lavertu, M. \& Buschmann, M. D. Ionization and Solubility of Chitosan Solutions Related to Thermosensitive Chitosan/Glycerol-Phosphate Systems. Biomacromolecules 8, 3224-3234 (2007).

52. Li, X. et al. Electron counting and beam-induced motion correction enable near-atomic-resolution single-particle cryo-EM. Nat. Methods 10, 584-590 (2013). 


\section{Materials and Methods}

\section{Materials}

DMG-PEG (MW 2000 Da) (DMG-PEG2000) was purchased from NOF America. Cholesterol was purchased from Combi Blocks. 1,2-distearoyl-sn-glycero-3-phosphocholine (18:0 PC, DSPC) was purchased from Avanti Polar Lipids. 4-Methyl-1-piperazinebutanamine was purchased from Enamine. Acryloyl chloride, sodium trimethylsilylpropanesulfonate (DSS) were purchased from Sigma Aldrich. 2-Octyl-1-dodecanol was purchased from BOC sciences. Tertiary butyl alcohol and neopentyl alcohol were purchased from combi-blocks. Unless otherwise noted, all reactions were carried out under ambient air atmosphere. All commercial reagents were used without further purification unless otherwise indicated. Bis(2-octyldodecyl) 3,3'-((4-(4-methylpiperazin-1yl)butyl)azanediyl)dipropionate (C24), and water-soluble analogues of C24 and MC3 were synthesized and purified as described below. Microfluidic cartridges compatible with the Spark NanoAssmblr ${ }^{\mathrm{TM}}$ were purchased from Precision Nanosystems. 3M sodium acetate $\mathrm{pH}=5.5$ was purchased from Thermofisher Scientific. The ONE-Glo Luciferase Assay System was purchased from Promega Corporation. Slide-A-Lyzer ${ }^{\mathrm{TM}}$ MINI Dialysis Device $0.5 \mathrm{ml}$ (MWCO, $10 \mathrm{KDa}$ ), 20X TE Buffer, RNAse-free and Quanti-iT Ribogreen RNA reagent were purchased from Thermo Fisher Scientific. Triton X-100 and 6-( $p$-toluidino)-2-naphthalenesulfonic acid sodium salt (TNS) was purchased from Sigma. The firefly luciferase (FLuc) sequence was cloned into an mRNA production plasmid (optimized 3' and 5' UTR and containing a 101 polyA tail), in vitro transcribed using N1-methylpseudouridine modified nucleoside, co-transcriptionally capped using the CleanCap technology (TriLink) and cellulose purified ${ }^{45}$ to remove dsRNA. The prefusion diproline stabilized SARS-CoV-2 Spike protein (S2P) sequence was codon optimized, and produced as described above. Purified mRNA was ethanol precipitated, washed, resuspended in nuclease-

free water, and subjected to quality control (electrophoresis, dot blot, and transfection into human DCs). D-Luciferin (sodium salt) was purchased from REGIS technologies, INC. HEK293 cells were purchased from ATCC.

\section{Synthesis of ionizable lipids and ionizable lipid analogues}

Solvents were purchased from Sigma Aldrich, Combi blocks, Oakwood chemicals, Alfa Aesar, VWR and Thermofisher. Anhydrous methylene chloride (DCM), anhydrous tetrahydrofuran 
(THF) and anhydrous DMF were purchased from Sigma Aldrich. Reactions were monitored using Opt. $\mathrm{KMnO}_{4}$ glass-based Silica Plates, F254 thin layer chromatography plates (TLC) and column purification was done using silica gel chromatography (TLG-R10014BK-323) purchased from Silicycle. NMR spectra were recorded on a Bruker $400 \mathrm{MHz}$ Spectrometer using $\mathrm{CDCl}_{3}, \mathrm{D}_{2} \mathrm{O}$ (Sigma Aldrich), as d-solvents and internal standards $\left(\delta 7.26\right.$ for ${ }^{1} \mathrm{H}$ NMR and $\delta 77.00$ for ${ }^{13} \mathrm{C}$ NMR). Solutions of $1 \mathrm{M} \mathrm{NaOH}$ and $1 \mathrm{M} \mathrm{HCl}$ were purchased from Sigma Aldrich. Four internal NMR standards, piperazine, imidazole, chloroacetic acid, and acetic acid, were purchased from Sigma Aldrich and were selectively used for in situ NMR pH measurements.

\section{a) C24 ionizable lipid and water-soluble analogue}

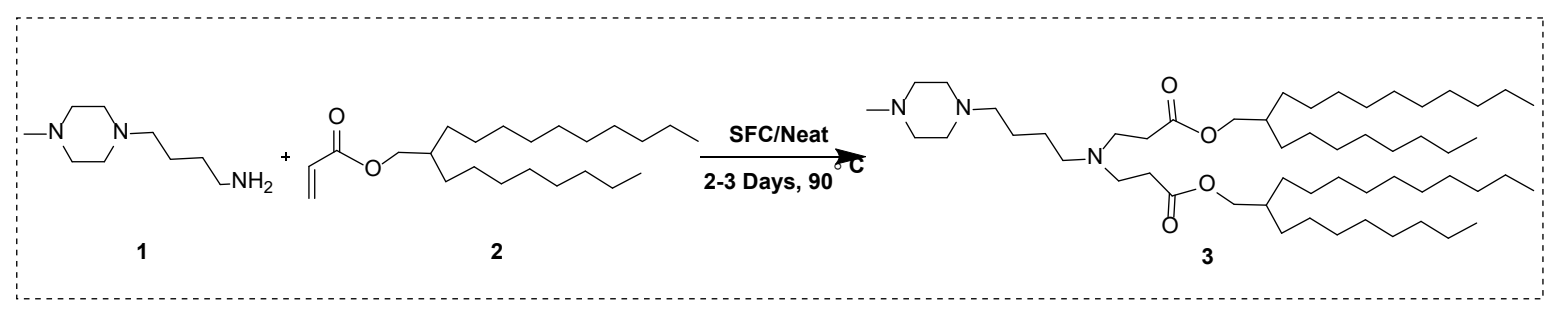

2-octyldodecyl acrylate ${ }^{2}$ (2) $(3.4 \mathrm{mmol}, 1.2 \mathrm{~g}, 1.48 \mathrm{ml})$ was added to an oven dried $5 \mathrm{ml}$ biotage microwave vial and 4-Methyl-1-piperazinebutanamine (1) $(1.31 \mathrm{mmol} ; 0.224 \mathrm{~g})$ was added dropwise $^{46}$. Solvent free conditions were maintained and the sealed microwave vial was stirred for 2-3 days at $90^{\circ} \mathrm{C}$. Reaction progress was monitored by TLC (chloroform/methanol 9:1 v/v, can be visualized with iodine stain, and Phospomolybdic Acid stain) until complete consumption of 1. The crude product was purified on a silica gel column eluted with chloroform containing 0-5\% methanol. Column fractions were analyzed by thin layer chromatography (TLC) and fractions containing pure product $\left(\mathrm{R}_{\mathrm{f}}=0.3\right)$ were concentrated, to obtain product (bis(2-octyldodecyl) 3,3'((4-(4-methylpiperazin-1-yl)butyl)azanediyl)dipropionate) as yellow oil (3). (0.77 g, 72\% yield). ${ }^{1} \mathrm{H}-\mathrm{NMR}:\left(400 \mathrm{MHz}, \mathrm{CDCl}_{3}, \delta=7.26 \mathrm{ppm}\right.$ as standard): $\delta 3.95$ (d, $\left.6.0 \mathrm{~Hz}, 4 \mathrm{H}\right), 2.76$ (t, $7.4 \mathrm{~Hz}$, 4H), 2.49-2.40 (m, 12H), 2.34 (t, $7.2 \mathrm{~Hz}, 2 \mathrm{H}), 2.30$ (s, 3H), 1.60 (s, br, 2H), 1.44-1.435 (m, 4H), $1.25(\mathrm{~m}, 64 \mathrm{H}), 0.87(\mathrm{t}, 6.8 \mathrm{~Hz}, 12 \mathrm{H}) .{ }^{13} \mathrm{C} \mathrm{NMR}:\left(100 \mathrm{MHz}, \mathrm{CDCl}_{3}, \delta=77.0 \mathrm{ppm}\right.$ as standard): $\delta$ 172.8(C), 67.2( $\left(\mathrm{CH}_{2}\right)$, 58.5 $\left(\mathrm{CH}_{2}\right)$, 55.1( $\left(\mathrm{CH}_{2}\right)$, 53.6( $\left(\mathrm{CH}_{2}\right)$, 53.2( $\left(\mathrm{CH}_{2}\right), 49.2\left(\mathrm{CH}_{2}\right), 46.0\left(\mathrm{CH}_{3}\right)$, 37.3(CH), 32.6( $\left(\mathrm{CH}_{2}\right), 31.94\left(\mathrm{CH}_{2}\right), 31.92\left(\mathrm{CH}_{2}\right), 31.2\left(\mathrm{CH}_{2}\right), 30.0\left(\mathrm{CH}_{2}\right), 29.7\left(\mathrm{CH}_{2}\right), 29.67\left(\mathrm{CH}_{2}\right)$, 29.60( $\left(\mathrm{CH}_{2}\right), 29.38\left(\mathrm{CH}_{2}\right), 29.35\left(\mathrm{CH}_{2}\right), 26.7\left(\mathrm{CH}_{2}\right), 25.2\left(\mathrm{CH}_{2}\right), 24.7\left(\mathrm{CH}_{2}\right), 22.7\left(\mathrm{CH}_{3}\right)$. Spectra are in Supplementary Figure 1. 


\section{C24-water-soluble analogue}

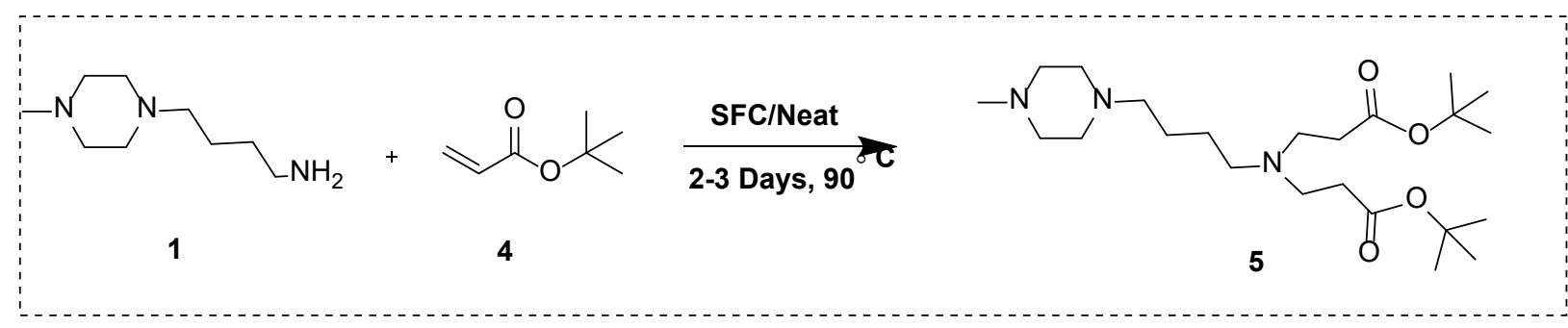

A mixture of 4-(4-methylpiperazin-1-yl)butan-1-amine (1) (1.16 mmol, $0.2 \mathrm{~g})$ and tert-Butyl acrylate $^{46}$ (4) (3.13 mmol, $\left.0.40 \mathrm{~g}\right)$, were added to an oven dried $5 \mathrm{ml}$ biotage microwave vial and solvent free conditions were maintained ${ }^{46}$. The sealed microwave vial was stirred for 2-3 days at $90^{\circ} \mathrm{C}$. Reaction progress was monitored by TLC (chloroform/methanol 9:1 v/v, can be visualized with iodine stain, and Phospomolybdic Acid stain), until complete consumption of $\mathbf{1}$. The crude product was purified on a silica gel column eluted with chloroform containing $0-5 \%$ methanol. Column fractions were analyzed by thin layer chromatography (TLC) and fractions containing pure product $\left(\mathrm{R}_{\mathrm{f}}=0.34\right)$ were concentrated, to obtain product as yellow oil (5). ( $0.30 \mathrm{~g}, 53 \%$ yield). ${ }^{1} \mathrm{H}-\mathrm{NMR}:\left(400 \mathrm{MHz}, \mathrm{CDCl}_{3}, \delta=7.26 \mathrm{ppm}\right.$ as standard): $\delta 2.67$ (t, $\left.7.2 \mathrm{~Hz}, 4 \mathrm{H}\right), 2.44-2.42(\mathrm{~m}, 9 \mathrm{H})$, 2.37-2.27 (m, 7H), 2.25 (s, 3H), 1.84-1.78 (m, 2H), 1.44-1.39 (m, 22H). ${ }^{13} \mathrm{C}$ NMR: (100 MHz, $\mathrm{CDCl}_{3}, \delta=77.0 \mathrm{ppm}$ as standard): $\delta 172.0(\mathrm{C}), 80.1(\mathrm{C}), 58.3\left(\mathrm{CH}_{2}\right), 54.9\left(2 \times \mathrm{CH}_{2}\right), 53.5\left(\mathrm{CH}_{2}\right)$, $52.9\left(2 \times \mathrm{CH}_{2}\right), 49.2\left(2 \times \mathrm{CH}_{2}\right), 45.8\left(\mathrm{CH}_{3}\right), 33.6\left(2 \times \mathrm{CH}_{3}\right), 28.0\left(9 \times \mathrm{CH}_{3}\right), 25.2\left(\mathrm{CH}_{2}\right), 24.5$ $\left(\mathrm{CH}_{2}\right)$. Spectra are in Supplementary Figure 1.

\section{c) DLin-MC3-DMA water-soluble analogue}

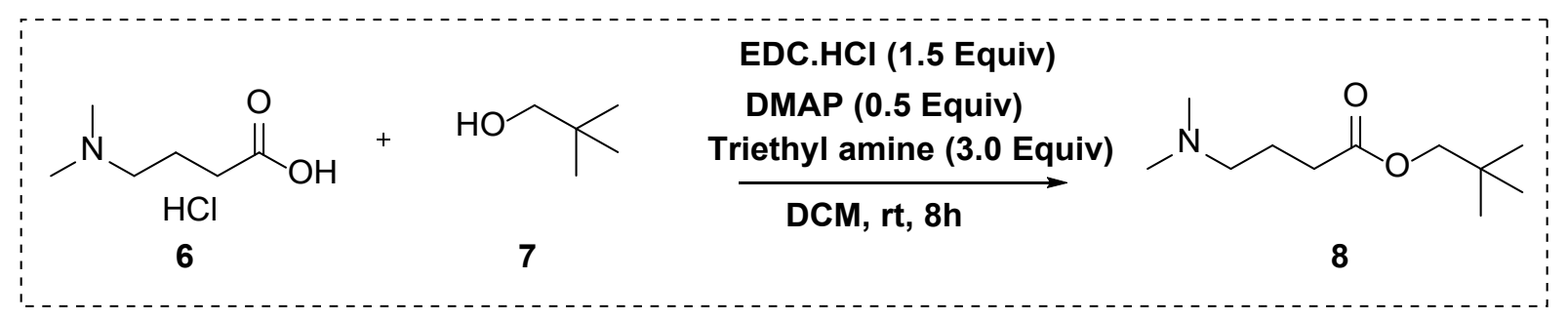

DLin-MC3-DMA water soluble analogue ( 8 above) was synthesized as per the previous literature reports $^{47,48}$. A mixture of 4-(dimethylamino)butanoic acid hydrochloride salt (6) (59.7 mmol, 1.0 g), 1-(3-dimethylaminopropyl)-3-ethylcarbodiimide hydrochloride (EDC $\cdot \mathrm{HCl})(7.16 \mathrm{mmol}, 0.63$ g), 4-(dimethylamino)pyridine (DMAP) (1.49 mmol, $0.18 \mathrm{~g})$, triethylamine (42.0 mmol, $4.25 \mathrm{~g}$, 
$5.83 \mathrm{~mL})$, and $\mathrm{CH}_{2} \mathrm{Cl}_{2}(100 \mathrm{~mL})$ were placed in a $250-\mathrm{mL}$ two-neck round bottom flask. The reaction was stirred for 20 minutes at room temperature and neopentyl alcohol (7) (7.16 mmol, $0.78 \mathrm{~mL}$ ) was added dropwise and the reaction stirred overnight. Reaction progress was monitored by TLC (chloroform/methanol 9:1 v/v, can be visualized with iodine stain) until complete consumption of $\mathbf{6}$ and the solvent $\mathrm{CH}_{2} \mathrm{Cl}_{2}$ was removed by rotary evaporation. The mixture was dissolved in $100 \mathrm{~mL}$ of $\mathrm{CH}_{2} \mathrm{Cl}_{2}$ and washed with $150 \mathrm{~mL}$ of water and $150 \mathrm{~mL}$ of saturated $\mathrm{NaHCO}_{3}$ solution. The organic phase was dried over magnesium sulphate and evaporated. The crude product was purified on a silica gel column eluted with chloroform containing $0-1 \%$ methanol. Column fractions were analyzed by thin layer chromatography (TLC) and fractions containing pure product $\left(\mathrm{R}_{\mathrm{f}}=0.4\right)$ were concentrated, to obtain product as yellow oil $(\mathbf{8})$. $(0.58 \mathrm{~g}$, $48 \%$ yield). ${ }^{1} \mathrm{H}-\mathrm{NMR}:\left(400 \mathrm{MHz}, \mathrm{CDCl}_{3}, \delta=7.26 \mathrm{ppm}\right.$ as standard): $\delta 2.36$ (t, $\left.7.4 \mathrm{~Hz}, 2 \mathrm{H}\right), 2.31$ (t, $7.2 \mathrm{~Hz}, 2 \mathrm{H}), 2.22\left(\mathrm{~s}, 6 \mathrm{H}, 2 \times \mathrm{NCH}_{3}\right), 1.84-1.78(\mathrm{~m}, 2 \mathrm{H}), 0.86\left(\mathrm{~s}, 9 \mathrm{H}, 2 \times \mathrm{CH}_{3}\right) .{ }^{13} \mathrm{C} \mathrm{NMR}:(100$ $\mathrm{MHz}, \mathrm{CDCl}_{3}, \delta=77.0 \mathrm{ppm}$ as standard): $\delta 173.6(\mathrm{C}), 73.6\left(\mathrm{CH}_{2}\right), 58.8\left(\mathrm{CH}_{2}\right), 45.3\left(2 \times \mathrm{CH}_{3}\right), 32.1$ $\left(\mathrm{CH}_{2}\right), 31.2(\mathrm{C}), 26.4\left(9 \times \mathrm{CH}_{3}\right), 22.9\left(2 \times \mathrm{CH}_{2}\right)$. Spectra are in Supplementary Figure 1.

\section{NMR measurement of pKa of water-soluble ionizable lipid analogues}

The $\mathrm{pH}$-dependence of proton NMR chemical shifts was used to measure the $\mathrm{pKa}$ 's of the ionizable lipid water-soluble analogues (WSA) following published methods ${ }^{5,6}$. Chemical shifts of piperazine, imidazole, 2-chloroacetic acid and acetic acid were used as internal $\mathrm{pH}$ indicators. Solutions for MC3-WSA were prepared with $100 \mathrm{mM} \mathrm{KCl,} 2 \mathrm{mM}$ piperazine, $2 \mathrm{mM}$ imidazole, and $5 \mathrm{mM}$ water soluble ionizable lipid analogue in $95 \% \mathrm{H}_{2} \mathrm{O}-5 \% \mathrm{D}_{2} \mathrm{O}$. Solutions for the terminal(N1) and aza amines(N2) at the $\beta$-position of carboxylic esters of C24-WSA were prepared with $100 \mathrm{mM} \mathrm{KCl,} 2 \mathrm{mM}$ piperazine, $2 \mathrm{mM}$ imidazole, $0.2 \mathrm{mM}$ DSS, and $5 \mathrm{mM}$ water soluble ionizable lipid analogue in $95 \% \mathrm{H}_{2} \mathrm{O}-5 \% \mathrm{D}_{2} \mathrm{O}$. Solutions for the internal amine (N3) of C24-WSA were prepared with $100 \mathrm{mM} \mathrm{KCl,} 2 \mathrm{mM}$ chloroacetic acid, $2 \mathrm{mM}$ acetic acid, $0.2 \mathrm{mM}$ DSS, and $5 \mathrm{mM}$ water soluble ionizable lipid analogue in $95 \% \mathrm{H}_{2} \mathrm{O}-5 \% \mathrm{D}_{2} \mathrm{O}$. Solutions were split into two equal volumes and one titrated to a lower $\mathrm{pH}$ using $0.1 \mathrm{M} \mathrm{HCl}$ and the other to an upper $\mathrm{pH}$ using $0.1 \mathrm{M} \mathrm{NaOH}$ where the lower and upper $\mathrm{pH}$ bracketed the desired range of $\mathrm{pH}$ (Supplementary Figure 2). Intermediate $\mathrm{pH}$ values were obtained by mixing different proportions of these two solutions. NMR measurements were performed on a Bruker $400 \mathrm{MHz}$ spectrometer where ${ }^{1} \mathrm{H}$ spectra were acquired at each of $\sim 24 \mathrm{pH}$ values ranging from the lower to upper $\mathrm{pH}$. 
Peaks for MC3 were calibrated to $\mathrm{D}_{2} \mathrm{O}\left(400 \mathrm{MHz}, \mathrm{D}_{2} \mathrm{O}, \delta=4.79 \mathrm{ppm}\right.$ as standard) and the peaks for C24 were calibrated to DSS (400 MHz, DSS, $\delta=0.00 \mathrm{ppm}$ as standard). Chemical shifts from piperazine, imidazole, 2-chloroacetic acid, and acetic acid were then used to calculate the $\mathrm{pH}$ of

each solution according to published methods ${ }^{5,6}$ and the chemical shifts of protons adjacent to each nitrogen in the ionizable lipid water sluble analogue headgroup were fit to the HendersonHasselbalch equation to provide the $\mathrm{pKa}$ of each Nitrogen. Spectra are in Supplementary Figure 2.

\section{Theoretical Calculation of pKa}

Experimentally determined pKa values from NMR, Zeta Potential and TNS assays were compared against theoretically calculated values using Advanced Chemistry Development, Inc. (ACD/Labs) software. The ACD/pKa database algorithmically estimates $\mathrm{pKa}$ values of whole molecules in an aqueous environment based on their constituent fragments using two approaches. The Classic algorithm employs a database of Hammett-type equations parameterized to cover most ionizable functional groups, each characterized by several equations involving variations of sigma constants. The Galas algorithm estimates $\mathrm{pKa}$ microconstants for all possible ionization centers in a hypothetical uncharged state based on the surroundings of the reaction center and neighboring ionization centers to produce microconstants from which $\mathrm{pKa}$ macroconstants are obtained. Classic algorithm calculations were used in this study.

\section{Preparation of mRNA Lipid Nanoparticles}

mRNA-loaded LNPs were formulated by preparing lipids in ethanol using \% mole ratios for ionizable-lipid/DSPC/Cholesterol/DMG-PEG2000 of 50/10/38.5/1.5 for MC3 and 48/13/37/2 for C24 and preparing mRNA in aqueous buffers. These two solutions were mixed in a Spark NanoAssmblr ${ }^{\mathrm{TM}}$ (Precision NanoSystems) at volumes and concentrations to achieve a molar ratio of ionizable lipid to phosphate on the mRNA backbone of 4 and ejected into PBS pH 7.4. The MC3 LNP was prepared using standard procedures described previously ${ }^{49}$ while C24 LNP assembly optimized some parameters for this specific formulation. The resulting mixtures were diluted 1:1 into PBS pH 7.4 and dialyzed against PBS to reach $\mathrm{pH}$ 7.3-7.4 after 6 buffer exchanges over 6 hours using a Slide-A-Lyzer MINI Dialysis Device (MWCO, 10 kDa). 


\section{Assay of mRNA Inaccessibility to Ribogreen}

Tris $(10 \mathrm{mM}, \mathrm{pH}=7.5) / \mathrm{EDTA}(1 \mathrm{mM})(\mathrm{TE})$ and Triton/TE $(2 \% \mathrm{v} / \mathrm{v}$ Triton in TE Buffer) were added in duplicates to a black microplate. Total mRNA in the LNP was diluted to $\sim 4 \mathrm{ng} / \mu \mathrm{L}$ in TE and added to each TE and TE/Triton well in a 1:1 volume ratio. Two standard curves were included in the Ribogreen Assay, one containing mRNA and TE, and the other containing mRNA and Triton/TE. Each standard curve was used to calculate the mRNA accessibility to ribogreen in each respective buffer. This approach using two standard curves is required, in comparison to a single standard curve in Triton/TE, which can overestimate inaccessibility by 5-10\%, since Ribogreen has higher background fluorescence in Triton/TE versus TE. Microplates were incubated at $37^{\circ} \mathrm{C}$ for 10 minutes to extract LNPs with Triton. Ribogreen reagent in DMSO was diluted 1:100 in TE Buffer and added to each well in a 1:1 volume ratio. Microplates were immediately introduced into the Cytation 5 Cell Imaging Multi-Mode Reader (Biotek) to read Fluorescence (Ex485/Em528).

\section{TNS Assay}

LNP pKa was determined using the TNS assay. The TNS reagent was prepared as a $300 \mu \mathrm{M}$ stock solution in DMSO. Following Sabnis et al $2018^{25}$, LNPs were diluted to $24 \mu \mathrm{M}$ ionizable lipid, TNS to $6.3 \mu \mathrm{M}$ in a total volume of $\sim 103 \mu \mathrm{L}$ of buffered solutions containing $20 \mathrm{mM}$ boric Acid, $10 \mathrm{mM}$ imidazole, $10 \mathrm{mM}$ sodium acetate, $10 \mathrm{mM}$ glycylglycine, $25 \mathrm{mM} \mathrm{NaCl}$, where the $\mathrm{pH}$ ranged from 3 to 10. The Cytation 5 Cell Imaging Multi-Mode Reader (Biotek) was used to read Fluorescence (Ex321/Em445). The pH was measured in each well after TNS addition. Mathematica (Wolfram Research) was used to fit the fluorescence data to the HendersonHasselbalch equation $\mathrm{RFU}=\mathrm{RFU}_{\max }-\left(\mathrm{RFU}_{\max }-\mathrm{RFU}_{\min }\right) /\left(1+10^{p K a-p H}\right)$ to provide the pKa.

mRNA LNP size, zeta potential (ZP), ZP pKa and pI, number of mRNA copies using dynamic light scattering and electrophoretic mobility

LNPs were diluted to $6.25 \mathrm{ng} / \mu \mathrm{L}$ total mRNA in PBS pH=7.4 and transferred into a quartz cuvette (ZEN2112) to measure size by Dynamic Light Scattering (DLS) in the Zetasizer Nano ZS (Malvern Panalytical) using particle RI of 1.45 and absorption of 0.001 in PBS at $25{ }^{\circ} \mathrm{C}$ with viscosity of $0.888 \mathrm{cP}$ and RI of 1.335 . Measurements were made using a $173^{\circ}$ backscatter angle of 
detection previously equilibrated to $25{ }^{\circ} \mathrm{C}$ for 30 seconds in duplicates, each with 5 runs and 10 second run duration, without delay between measurements. Each measurement had a fixed position of $4.65 \mathrm{~mm}$ in the quartz cuvette with an automatic attenuation selection. Data was analyzed using a General-Purpose model with normal resolution. Diameter are reported as the number-average that corresponds more closely to physical size seen in electron microscopy versus the zetaaverage $^{50}$. A molecular volume model described previously20 was used to estimate the number of mRNA copies in the LNP using the number average diameter to calculate LNP volume. LNPs were diluted into the TNS buffer described above at $\mathrm{pH}$ ranging from 3-10 for zeta potential measurement by Electrophoretic Light Scattering (ELS) in the Zetasizer Nano ZP (Malvern Panalytical) using the same material and dispersant parameters described above and the Smoluchowski model. Each measurement had voltage set manually at 80 Volts to avoid ohmic heating that occurred if voltage was set automatically. Measurements in the disposable folded capillary cuvette with an automatic attenuation selection for photon counts were made in triplicates for 20 runs each, and 30 second delay between each replicate. Mathematica was used to fit zeta potential data to the data to the extended ${ }^{34}$ Henderson-Hasselbalch equation $\Psi=\Psi_{\max }-$ $\left(\Psi_{\max }-\Psi_{\min }\right) /\left(1+10^{(p K a-p H) / n}\right)$ to provide the $\mathrm{pKa}, \mathrm{n}$ and low $\mathrm{pH}$ and high $\mathrm{pH}$ zeta potential limits $\Psi_{\max }$ and $\Psi_{\min }$, respectively. The extended model is used here, since the LNP pKa is ionization-state-dependent in a way similar to a polyelectrolyte ${ }^{34,51}$. TNS data did not require the extended model since TNS dye binding only detects LNP surface charge. The isoelectric pI was the $\mathrm{pH}$ found by interpolating zeta potential to zero.

\section{Cryoelectron miscroscopy}

Grids for electron microscopy were plunge-frozen using a Vitrobot Mark IV system. The chamber was set to $25^{\circ} \mathrm{C}$ and $100 \%$ humidity. LNPs $(3 \mu \mathrm{L})$ were applied to grids (ultrathin carbon film on lacey carbon support, Ted Pella \#01824G), incubated for 1 minute, and blotted twice for $3 \mathrm{~s}$ each time at a blot force of 25 before plunging into liquid ethane. Grids were imaged on a Talos Arctica system (Thermo Fisher Scientific) at $200 \mathrm{kV}$ with a Falcon 3EC detector, using EPU for data collection. The nominal magnification was $45,000 \mathrm{x}$, with a calibrated pixel size of $0.223 \mathrm{~nm}$. Images were collected in integrating mode using $5 \mathrm{~s}$ exposures, with a total dose of $60 \mathrm{e} / \AA 2$, and 66 fractions which were motion-corrected using Motioncor $2^{52}$. 
In vivo live animal imaging for luciferase expression following intramuscular administration of C24 and MC3 LNPs containing FLuc mRNA

The investigators adhered to the "Guide for the Care and Use of Laboratory Animals"' by the Committee on Care of Laboratory Animal Resources Commission on Life Sciences, National Research Council. Mouse studies were conducted under protocols approved by the Institutional Animal Care and Use Committees (IACUC) of the University of Pennsylvania (UPenn). All animals were housed and cared for according to local, state, and federal policies in an Association for Assessment and Accreditation of Laboratory Animal Care International (AAALAC)accredited facility. 8-week old female Balb/c mice purchased from Charles Rivers and acclimatized at the University of Pennsylvania for 7 days before experiments. Mice were injected with $5 \mu \mathrm{g}$ or $0.5 \mu \mathrm{g}$ FLuc mRNA-LNP using a 3/10 $\mathrm{cm}^{3} 29 \mathrm{G}$ insulin syringe (BD Biosciences). mRNA-LNPs were diluted in PBS and injected into the gastrocnemius muscle $(50 \mu \mathrm{L}$ injection volume). At 4 hours post-injection, mice were anesthetized with $2 \%$ isofluorane in oxygen and imaged $10 \mathrm{~min}$ after intraperitoneal injection of $250 \mu \mathrm{L}$ D-Luciferin $(15 \mathrm{mg} / \mathrm{ml})$. Bioluminescence imaging was performed using an IVIS Spectrum imaging system (Caliper Life Sciences). Imaging was repeated at 24 hours and animals were euthanized. A longevity experiment imaged animals each day for 5 days. Legs were also fixed at $24 \mathrm{hrs}$ post administration and injection sites fixed in neutral buffered formalin, processed in paraffin, and stained with hematoxylin and eosin.

Immunogenicity in Balb/c mice of $\mathrm{C} 24$ and MC3 LNPs containing the nucleoside-modified S2P SARS-CoV-2 immunogen

Balb/c mice (Charles rivers) were administered C24 and MC3 LNPs containing 0.1, 0.25, 0.5, 1.0 $\mu \mathrm{g}$ of the nucleoside-modified mRNA-encoded S2P immunogen ( $\mathrm{N}=5$ animals per dose per LNP) in $50 \mu 1$ injected into the medial gastrocnemius muscle The two injections were spaced 3 weeks apart and blood was collected through the retro-orbital route one day prior to the first injection (Pre-bleed), prior to the second injection (Prime) and 2 weeks after the second injection (Boost). Serum was separated from blood following an incubation period of 30 minutes at room temperature, and samples were centrifuged at 10,000 g for 5 minutes in a non-refrigerated Eppendorf 5424 centrifuge (Eppendorf, Enfield, CT, USA). Separated serum was stored at $-20^{\circ} \mathrm{C}$ until used. Total antibody titers were determined using an Endpoint Enzyme Linked ImmunoSorbent Assay (ELISA). Briefly, High Bind Stripwell ${ }^{\mathrm{TM}}$ Corning 96 Well Clear 
Polystyrene Microplates were coated overnight with $1 \mu \mathrm{g} / \mathrm{ml}$ purified SARS-CoV-2 RBD (cat\# Z03501), washed once with wash buffer (0.05\% Tween-20 in PBS), and blocked for two hours at room temperature using 2\% w/v BSA in PBS. Plates were then washed three times, and mouse sera was added at 1:27,000 (prime sera) and 1:54,000 (boost sera)and in the blocking solution and incubated for 2 hours at room temperature, washed three times before incubation with (HRP)conjugated anti-mouse secondary antibody in blocking buffer (1:10 000) for 1.5 hours. After incubation, plates were washed three times before the addition of $100 \mu 1$ per well of KPL TMB substrate for 8 minutes. The reaction was stopped using $2 \mathrm{~N}$ sulfuric acid, and the absorbance measured at 450nm using a SpectraMax ${ }^{\mathrm{TM}} 190$ microplate reader. To determine neutralization potential, a VSV $\Delta$ G-RFP pseudotyped virus (50-200 focus forming units/well) was incubated with 2-fold serially diluted serum samples and incubated for $1 \mathrm{~h}$ at $37^{\circ} \mathrm{C}$ prior to addition of the virusantibody mixture to VeroE6 TMPRSS2 cells. 20 hours post infection, the cells were washed and fixed with 4\% paraformaldehyde before visualization on an S6 FluoroSpot Analyzer (CTL, Shaker Heights $\mathrm{OH}$ ). Individual infected foci were enumerated and the values compared to control wells without antibody. The Focus Reduction Neutralization Titer 50\% (FRNT 50 ) was measured as the greatest serum dilution at which focus count was reduced by at least $50 \%$ relative to control cells that were infected with pseudotype virus in the absence of mouse serum. FRNT $_{50}$ titers for each sample were measured in two technical replicates performed on separate days.

\section{Protection against SARS-CoV-2 lethal challenge in K18-hACE2 mice by immunization with C24 and MC3 LNPs containing the nucleoside modified S2P SARS-CoV-2 immunogen}

Female B6;SJL-Tg(K18-hACE2)2Prlmn/J (hACE2) mice purchased from Jackson Laboratory K18-hACE2 mice were administered C24 and MC3 LNPs containing 0.1, 0.25, 0.5, $1.0 \mu \mathrm{g}$ of the nucleoside-modified mRNA-encoded S2P immunogen ( $\mathrm{N}=5$ animals per dose per LNP) in $50 \mu 1$ injected into the medial gastrocnemius muscle. The mice received a prime and a boost injection of the mRNA LNPs and the two injections were spaced 6 weeks apart. Blood was collected by mandibular bleeds prior to the first injection (Pre-bleed), prior to the second injection (Prime) and 2 weeks after the second injection (Boost). Neutralizing antibodies were assessed by Plaque Reduction Neutralization Titer Assay (PRNT) (described below). SARS-CoV-2 propagation was done in a cell culture flask seeded with Vero cells at $60-75 \%$ confluency. The cells were infected with SARS-CoV-2 Italy Isolate -INMI1 (from BEI Resources). Infection was carried out for 48- 
72 hours after which the supernatant was recovered, and viral titer assessed by plaque assay. Mice were challenged 2 weeks after the second immunization with SARS-CoV-2 by intranasal administration at dose of $5 \times 10^{5} \mathrm{pfu}$ and followed until death or euthanasia criteria were met. Weight and temperature were recorded daily. Two of the 5 mice in each group were sacrificed on day 5 post-challenge to assess lung viral titers by plaque assay. Lung tissues were homogenized and spun down. The supernatant recovered for assessment of viral load by plaque assay. The remaining three mice were monitored daily for signs of morbidity and mortality. Weight and temperature reading were also recorded daily for the surviving mice until the end of the study.

For PRNT50 assays, mouse sera were diluted 1:10 in DMEM (supplemented with 5\% FBE, 1\% L-glutamate and $20 \mathrm{U} / \mathrm{mL}$ penicillin, and $20 \mu \mathrm{g} / \mathrm{mL}$ streptomycin). Serial two-fold dilutions were then prepared from the 1:10 dilution and mixed with 100 pfu of SARS-CoV-2 virus and incubated at $37^{\circ} \mathrm{C}$ for $1 \mathrm{~h}$. The sera/virus mixture was then overlayed onto a confluent layer of Vero cells in a 12-well plate format and incubated for $1 \mathrm{~h}$ at $37^{\circ} \mathrm{C}$ incubator with $5 \% \mathrm{CO}_{2}$. The inoculated wells were then overlaid with a 1:1 mixture of Eagle's Minimum Essential Medium (without phenol red, supplemented with 5\% FBE, nonessential amino acids, $1 \mathrm{mM}$ sodium pyruvate (VWR, 45000710, Dixon, CA, USA), $2 \mathrm{mM}$ L-glutamine, $20 \mathrm{U} / \mathrm{mL}$ penicillin, and $20 \mu \mathrm{g} / \mathrm{mL}$ streptomycin) and $0.6 \%$ agarose (ThermoFisher, 16500100 ) and incubated for $48 \mathrm{~h}$ at $37^{\circ} \mathrm{C}$ with $5 \% \mathrm{CO}_{2}$. Cells were then fixed with $10 \%$ formaldehyde (FisherSci, F79p-4) for $1 \mathrm{~h}$. Media was removed, cells were washed with $\mathrm{diH}_{2} \mathrm{O}$ and stained with $1 \%$ crystal violet (FisherSci, C581-25) and 20\% ethanol solution (FisherSci, BP2818-4). Plaques were counted and plotted as pfu/dilution.

For plaque assays, the Vero cells (WT Veros, ATCC) were plated in 12-well plates at a density of $2 \mathrm{X} 10^{5}$ cells per well and incubated overnight. Supernatants from tissue homogenates were serially diluted to $10^{-6}$ and overlaid on cells for $1 \mathrm{~h}\left(37^{\circ} \mathrm{C}, 5 \% \mathrm{CO}_{20}\right)$. Cells were then overlaid with Eagle's Minimum Essential Medium (without phenol red, supplemented with 5\% FBE, nonessential amino acids, $1 \mathrm{mM}$ sodium pyruvate (VWR, 45000-710, Dixon, CA, USA), $2 \mathrm{mM} \mathrm{L-glutamine,} 20 \mathrm{U} / \mathrm{mL}$ penicillin, and $20 \mu \mathrm{g} / \mathrm{mL}$ streptomycin) with $0.6 \%$ agarose (ThermoFisher, 16500100) and incubated for $48 \mathrm{~h}$. Cells were then fixed with $10 \%$ formaldehyde (FisherSci, F79p-4) for $1 \mathrm{~h}$. Medium was removed, cells were washed with $\mathrm{diH}_{2} \mathrm{O}$ and stained with $1 \%$ crystal violet (FisheSci, C581-25) and 20\% ethanol solution (FisherSci, BP2818-4). Plaques were manually counted and datasets represent plaque forming units per milliliter $(\mathrm{PFU} / \mathrm{mL})$. 


\section{Storage/Stability Studies of mRNA LNPs}

$\mathrm{C} 24$ and MC3 LNPs containing FLuc mRNA were stored in PBS at $4^{\circ} \mathrm{C}$ or at room temperature $\left(\mathrm{RT} \approx 22^{\circ} \mathrm{C}\right)$. They were assayed on days $0,2,4,7,14$ of storage for size by DLS as described above, mRNA encapsulation as described above and for bioactivity via transfection into HEK293 cells and assessment of luciferase expression. For bioactivity, HEK293 cells were seeded in white 96-well plates at a density of $12 \times 10^{3}$ cells per well in $100 \mu$ L EMEM medium ( $10 \%$ FBS) the day before transfection and incubated at $37^{\circ} \mathrm{C} 5 \% \mathrm{CO}_{2}$. FLuc mRNA-loaded LNPs were diluted so that $8 \mu \mathrm{L}$ contained $25 \mathrm{ng}$ mRNA FLuc and HEK293 cells were transfected at this dose using triplicates 24 hours after seeding. After a further 24 hours for transfection, $100 \mu \mathrm{L}$ of One-Glo substrate was added directly to the wells to detect luciferase expression based on luminescence in Cytation 5 luminometer plate reader. Additional C24 and MC3 LNPs containing FLuc mRNA were stored for 19 days in PBS at $4^{\circ} \mathrm{C}$, RT and $37^{\circ} \mathrm{C}$. FLuc mRNA was extracted from LNPs using chloroform/methanol and analyzed for mRNA integrity via microfluidic electrophoresis on a 2100 Bioanalyser (Agilent) following manufacturer's instructions. mRNA concentration was quantified by Nanodrop, then diluted to $1 \mathrm{ng} / \mathrm{ul}$ to load $1 \mathrm{ng}$ mRNA of each sample in the Bioanalyser. The $\%$ mRNA integrity was calculated by integrating the area under the curve (AUC) of the main mRNA FLuc peak and normalizing to the average day 0 value for C24 and MC3 LNPs taken together.

\section{Statistics and Reproducibility}

The Linear Least Squares Multivariate Model in the JMP Pro 15.1.0 software was used to perform comparisons between groups in Figures 1 and 3. For In Vivo IVIS imaging data the 4 and 20/24 hour time points were considered repeated measures. $\log _{10}$ transformations were applied to FRNT50 and viral titers. Linear regression models were used to compare OD and transformed FRNT50 and viral titers by LNP adjusted for dose in Figures 4a-4c, 5d, and 5h. Unadjusted linear regression with LNP as a predictor was used to compare neutralization of pseudovirus in Figure 4d. The proportion of mice dead after lethal challenge of SARS-CoV-2 was compared by LNP using Fishers Exact Test, excluding PBS (Figure 5a). Linear mixed effects models with dose, dilution, and LNP as fixed effects and a random intercept for mouse evaluated the effect of LNP on the percent of virus detected (Figures $5 \mathrm{bcfg}$ ). Linear regression and mixed effects models were run in $\mathrm{R}$ version 3.6.3. 


\section{Acknowledgements}

M.D.B. acknowledges financial support from the Commonwealth Research Commercialization Fund (CRCF) Center for Innovative Technology (CIT) Award ER17-002-LS. M.P. acknowledges supported by resources provided by the Office of Research Computing at George Mason University (URL: https://orc.gmu.edu) and by grants from the National Science Foundation (Awards Number 1625039 and 2018631).

\section{Disclaimer}

Certain commercial equipment, instruments, materials, suppliers, or software are identified in this paper to foster understanding. Such identification does not imply recommendation or endorsement by the National Institute of Standards and Technology (NIST), nor does it imply that the materials or equipment identified are necessarily the best available for the purpose.

\section{Author contributions}

S.A., M.C., M.G.A., M.P., A.N., P.G., D.W., P.B., T.C., A.G., M.D.B. conceived and designed the experiments and wrote the manuscript. M.C., S.A., T.C., A.G., H.S., L.W., F.A., P.H. T.B.M. K.R.H., O.S, performed experiments. A J S-S performed statistical analyses. All authors discussed the results and commented on the manuscript. M.D.B. directed the research.

\section{Competing interests}

M.D.B., M.P., S.A., M.C., D.W., M.G.A. are founders of AexeRNA Inc that owns rights to commercialization of lipid nanoparticle mRNA delivery systems including C24 described in this report.

\section{Data availability}

The source data for the graphs and charts in the figures is available as Supplementary data Files. The data that support the plots within this paper and other findings of this study are available from the corresponding author upon reasonable request. 
Figure 1. The multiprotic C24 ionizable lipid produces multistage protonation in the LNP and greater protonation in the endosomal pH range than the MC3 LNP. a) Structures of C24 and MC3 and their water-soluble analogues showing theoretical pKas. The C24 ionizable lipid (MW 876.49) has two rapidly degradable ester bonds each linked to an asymmetric branched C8C10 (bis 2-octyldodecyl) alkyl tail. The headgroup of C24 is trivalent with theoretical pKas of 7.8, 4.1 and 7.7 calculated using the ACDLabs Percepta Classic algorithm. MC3 (MW 642.11) has one slowly degradable ester linked to a di-linoleic tail and a monovalent head group with a theoretical $\mathrm{pKa}$ of 9.4. b) The pKa of each nitrogen in the $\mathrm{C} 24$ ionizable lipid was measured using the $\mathrm{pH}-$ dependence of the 1H NMR chemical shift of protons adjacent to each nitrogen using the water soluble analogue in the inset. Spectra are shown in Supplementary Figure 2. Fitting of the chemical shifts versus $\mathrm{pH}$ to the Henderson Hasselbalch equation provides the $\mathrm{pKa}$ of each nitrogen and are similar to within 0.4 units of the pKas predicted by ACDLabs Percepta Classic algorithm shown in (a). The stretched appearance of the titration of the terminal nitrogen (red) suggests interaction of its protonated form with the nitrogen closest to the linker (blue) that protonates simultaneously possibly coordinating these two nitrogen atoms. c) The pKa of the dimethylamine nitrogen of MC3 was measured using the $\mathrm{pH}$-dependence of the $1 \mathrm{H}$ NMR chemical shift of dimethylamine protons and fitting to the Henderson Hasselbalch equation. The measured pKa of 9.5 agreed with the value 9.4 predicted by ACDLabs Percepta Classic algorithm shown in (a). d) The LNP pKa was measured with the TNS dye-binding assay for C24 and MC3. The TNS pKa measures surface charge and cannot reflect protonation below $\mathrm{pH} \approx 6$. Equal amounts of ionizable lipid were used in the assay for $\mathrm{C} 24$ and $\mathrm{MC} 3$ so that the higher RFU of $\mathrm{C} 24$ for $\mathrm{pH}$ below 7 indicates a higher level of surface protonation of the C24 LNP in the endosomal $\mathrm{pH}$ range where t-tests comparing RFU of $\mathrm{C} 24$ to MC3 at pH 6 and 6.5 showed significant differences $\mathrm{p}<0.05$ (*) $^{*}$ (mean +/- SD for N=3). e) Net LNP charge and ionization was measured using electrophoretic mobility to provide Zeta Potential over the $\mathrm{pH}$ range 3-10. Electrophoretic mobility depends on net charge of the LNP and can detect protonation through the entire $\mathrm{pH}$ range including endosomal $\mathrm{pH}$ values down to 4.5 when endosomes fuse with lysosomes. For the monoprotic MC3 ionizable lipid, the Zeta Potential fits the extended Henderson Hasselbalch equation (solid line) developed originally for polyelectrolytes since it captures the ionization state dependence of $\mathrm{pKa}$ of the multivalent LNP containing thousands of strongly interacting MC3 molecules in close proximity within the LNP. For C24, the zeta potential does not fit well the extended Henderson Hasselbalch model accurately 
(dotted versus solid red lines) since each $\mathrm{C} 24$ has 3 nitrogens with different $\mathrm{pKa}$ shown in $\mathrm{b}$. The two peripheral nitrogens will protonate at higher $\mathrm{pH}$ values while the internal, central nitrogen creates the steeply increasing zeta potential at $\mathrm{pH}$ values below 4.5. The C24 LNP produces a more negative zeta potential at neutral $\mathrm{pH}$ that rises rapidly as $\mathrm{pH}$ drops in the endosomal $\mathrm{pH}$ range indicating greater endosomal protonation for $\mathrm{C} 24$ than for $\mathrm{MC} 3$ and t-tests comparing $\mathrm{ZP}(\mathrm{mV})$ of $\mathrm{C} 24$ to MC3 at $\mathrm{pH} 7.4$ showed significant differences $\mathrm{p}<0.001\left(^{*}\right)$ (mean $+/-\mathrm{SD}$ for $\mathrm{N}=3$ ). f) $\mathrm{pKa}$ predicted from the ACD Percepta Classic algorithm compared to that measured by NMR on water soluble analogues and the TNS pKa, Zeta Potential (ZP) pKa, ZP isoelectric pI, the increase in TNS RFU from $\mathrm{pH} 7.4$ to 6 and the increase in Zeta Potential from $\mathrm{pH} 7.4$ to 4.5. The NMR pKa agrees with the theoretically predicted $\mathrm{pKa}$ and are significantly higher than the LNP $\mathrm{pKa}$ measured by both TNS and Zeta Potential. We recently explained this difference between molecular and colloidal $\mathrm{pKa}$ as mainly due to proton partitioning between the lipid phase of the LNP and the aqueous medium ${ }^{20}$. The increase in TNS RFU from pH 7.4 to 6 and the increase in Zeta Potential from $\mathrm{pH} 7.4$ to 4.5 for $\mathrm{C} 24$ are nearly double that of $\mathrm{MC} 3$ indicating that both surface LNP protonation (TNS) and net LNP charge (ZP) increase more for C24 than MC3 in the endosomal $\mathrm{pH}$ range. 
a

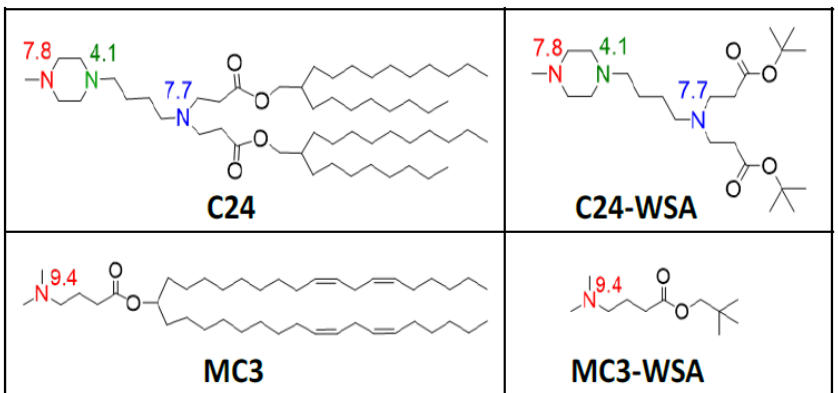

b
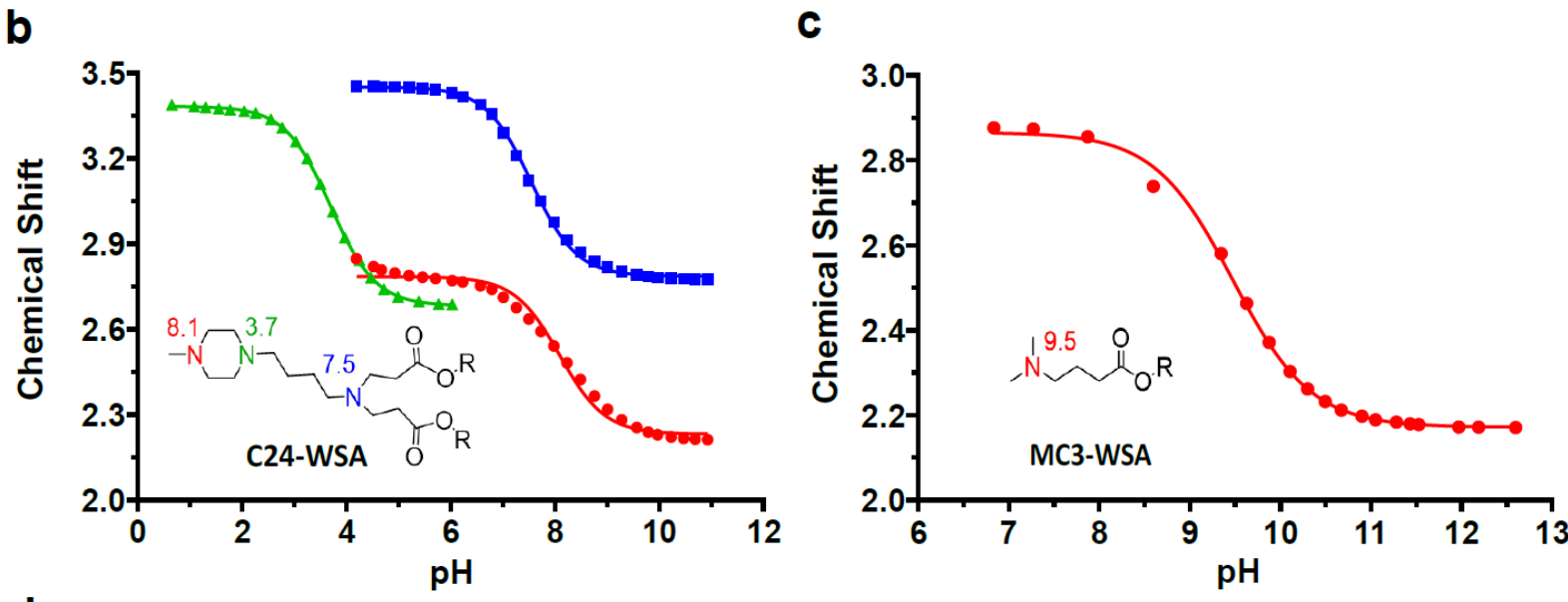

d

e
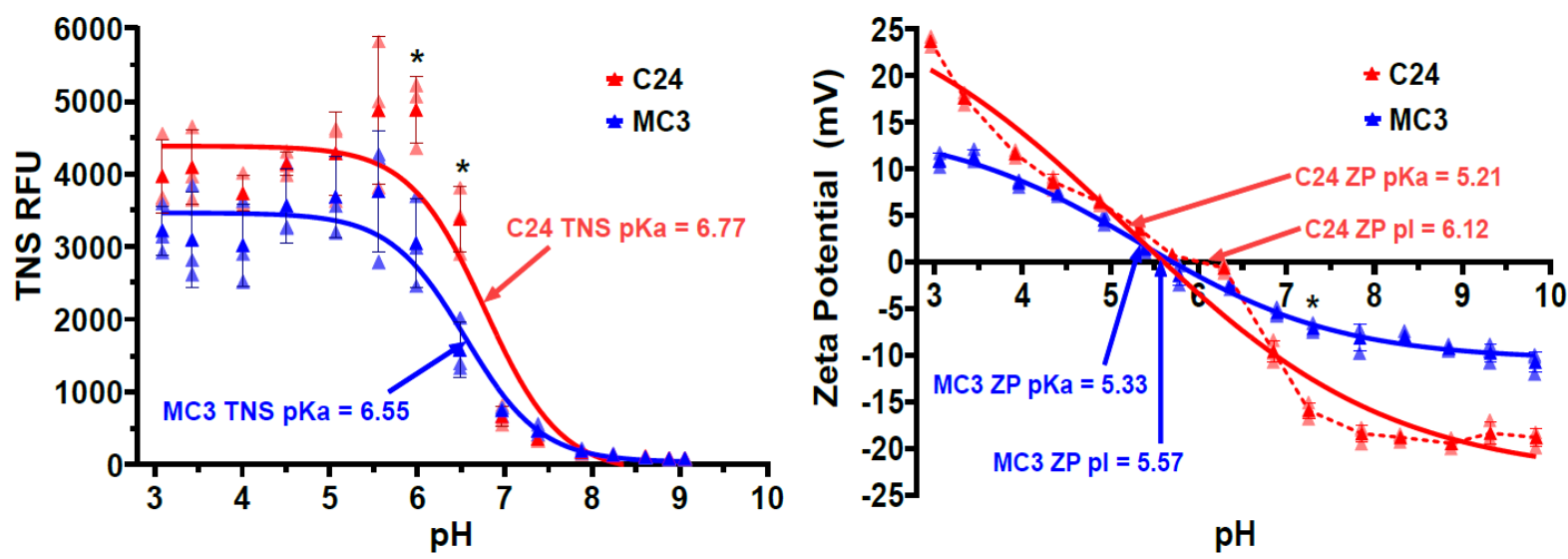

\begin{tabular}{|c|c|c|c|c|c|c|c|}
\hline $\begin{array}{c}\text { Ionizable } \\
\text { Lipid }\end{array}$ & $\begin{array}{c}\text { pKa, } \\
\text { ACD } \\
\text { Classic }\end{array}$ & $\begin{array}{c}\text { pKa, } \\
\text { NMR }\end{array}$ & $\begin{array}{c}\text { pKa, } \\
\text { TNS }\end{array}$ & $\begin{array}{c}\text { pKa, } \\
\text { ZP }\end{array}$ & $\begin{array}{c}\text { pl, } \\
\text { ZP }\end{array}$ & $\begin{array}{c}\Delta \text { TNS } \\
6-7.4 \\
\text { (RFU) }\end{array}$ & $\begin{array}{c}\Delta \text { ZP } \\
\begin{array}{c}4.5-7.4 \\
\text { (mV) }\end{array}\end{array}$ \\
\hline C24 & $\begin{array}{c}7.8, \\
4.1, \\
7.7\end{array}$ & $\begin{array}{c}8.1, \\
3.7,\end{array}$ & 6.77 & 5.21 & 6.12 & 4517 & 25.1 \\
\hline MC3 & 9.4 & 9.5 & 6.55 & 5.33 & 5.57 & 2559 & 14.3 \\
\hline
\end{tabular}


Figure 2. Structural properties of C24 and MC3 lipid nanoparticles. a) DLS number-averaged size showed C24 LNPs were slightly larger and with lower polydispersity index than MC3 LNPs. b) The ribogreen assay showed slightly lower levels of mRNA inaccessible to ribogreen for C24 versus MC3. We performed this assay using 2 standard curves, with and without triton. When only one standard curve with triton is used (such as in most publications to date) the mRNA inaccessible to ribogreen increases by $\sim 8 \%$ shown in the yellow hatched portions. This assay is often interpreted as \% encapsulation efficiency versus \% mRNA inaccessible to ribogreen shown here. The latter is more accurate since it has been shown that dye accessibility of mRNA does not indicate that the mRNA is free and unencapsulated ${ }^{35}$. It may however reflect a different packing and internal structure of the LNP. c) mRNA copy number was calculated using a previously published molecular volume $\operatorname{model}^{20}$ and the number-weighted average diameter of each LNP. We estimated the molecular volume of the $\mathrm{C} 24$ ionizable lipid as proportional to its $\mathrm{MW}$ at $1.76 \mathrm{~nm} 3$ versus 1.29 nm3 for MC3. d) CryoTEM of MC3 and C24 (E) revealed sizes consistent with DLS numberaveraged size. Both LNPs have a peripheral bilayer consistent with DSPC localization in this zone as described previously ${ }^{36}$. 
a

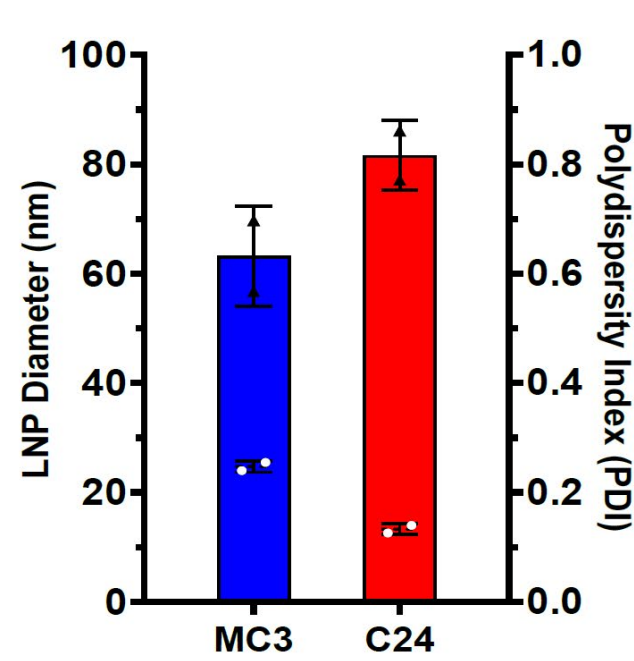

d

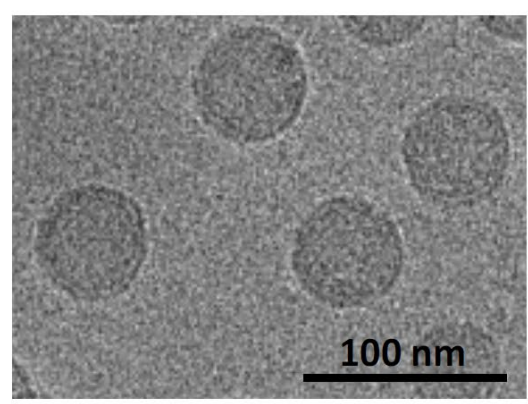

b

के

e

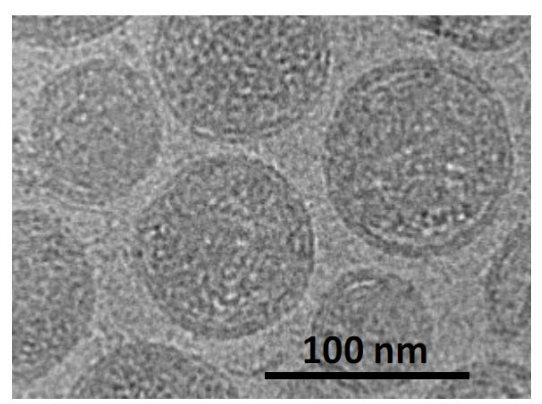

C

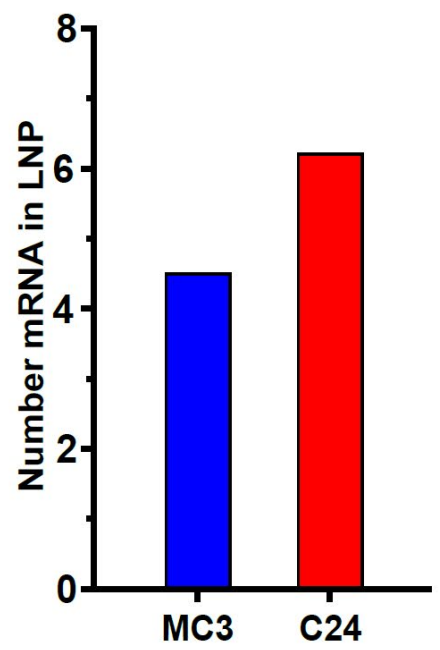


Figure 3. Luciferase expression after intramuscular (IM) administration in Balb/c mice shows significantly higher on-target and lower off-target mRNA expression with the C24

LNP than for MC3. a) In vivo imaging at $4 \mathrm{~h}$ and $24 \mathrm{~h}$ after IM administration of a $5 \mu \mathrm{g}$ dose of FLuc in LNPs show higher intramuscular expression (green ROIs) of Fluc delivered using C24 compared to $\mathrm{MC} 3$ and also revealed significant systemic distribution of MC3 resulting in off-target expression in liver (red ROIs). b) At this high $5 \mu \mathrm{g}$ dose C24 has a significantly higher intramuscular expression than MC3 where $p=0.0074$ for the effect of LNP in a multivariate analyses of photon Flux as a function of LNP (MC3/C24) and time (4hr/24h). c) Off-target Fluc expression in liver after IM administration is $6 \mathrm{X}$ lower for C24 versus MC3 where $\mathrm{p}=0.051$ in a ttest comparing LNPs. d) When a low dose $(0.5 \mu \mathrm{g})$ more representative of vaccinations is administered, FLuc in the muscle at $4 \mathrm{hrs}$ is $\sim 4$ fold higher for C24 versus MC3 where $\mathrm{p}=0.0034$ (in e) for the effect of LNP in a multivariate analysis of Flux as a function of LNP (MC3/C24) and time (4hr/24h). f) The duration of Luciferase expression for a $5 \mu \mathrm{g}$ dose administered IM was followed over 5 days showing a rapid decrease over the first 2 days followed by a slower decline in expression. 
a
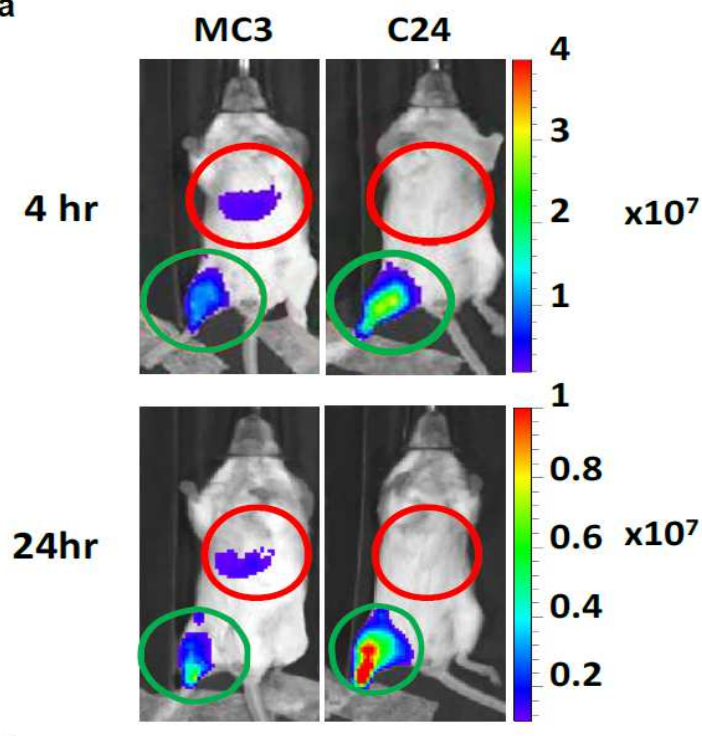

d
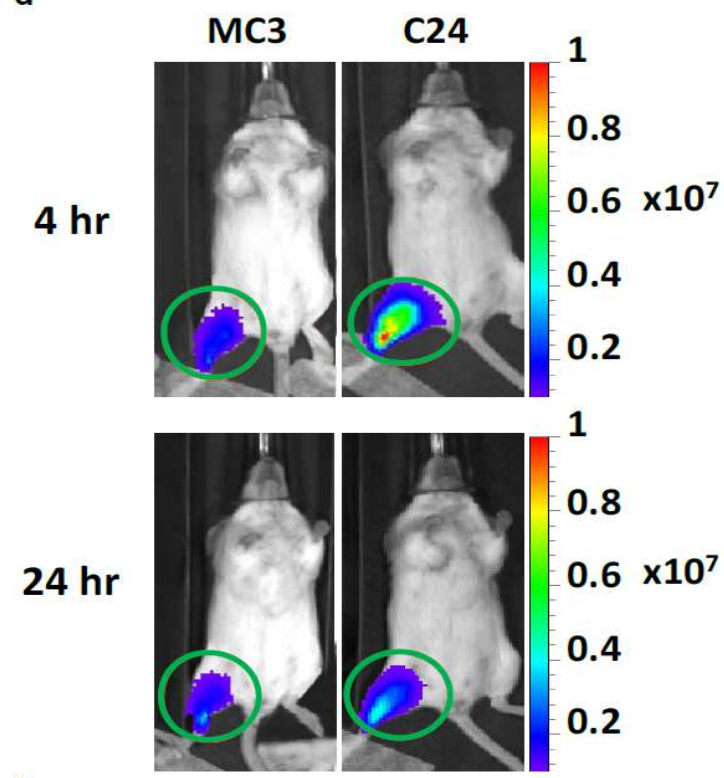

f

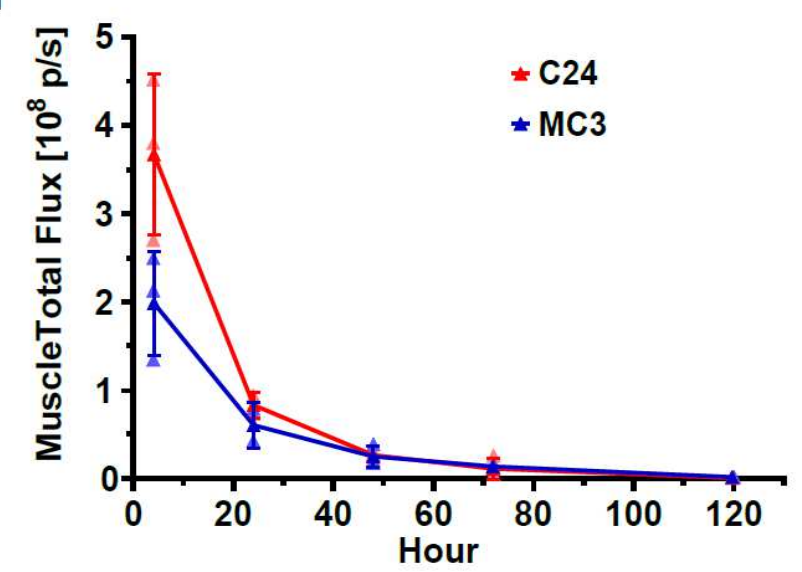

b

C

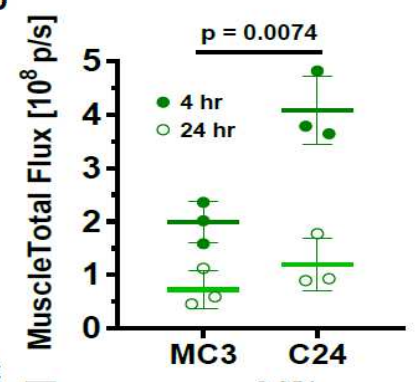

क $37 \quad p=0.051$

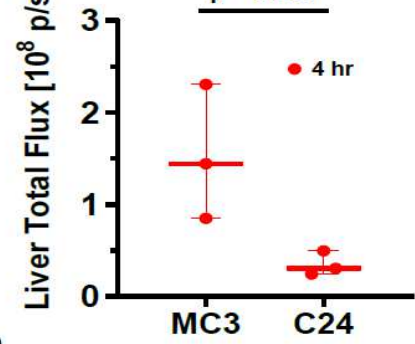

e

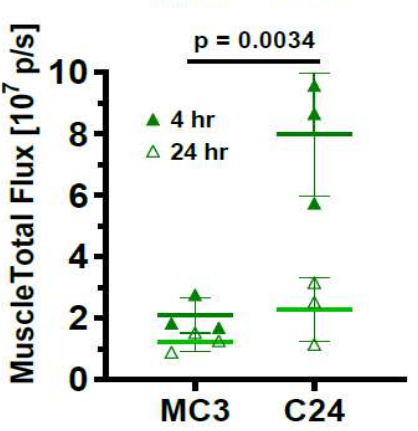


Figure 4. C24 LNPs generate 10 fold higher binding and pseudoneutralizing antibody titers than MC3 LNPs in immunogenicity studies with Balb/c mice. C24 and MC3 LNPs containing a nucleoside-modified mRNA encoding for a diproline stabilized membrane-bound spike protein (S2P) of SARS-CoV-2 were administered to Balb/c mice at 4 doses ranging from 0.1 to $1 \mu \mathrm{g}$. a) ELISA optical density at the transitional dilution of 27,000 for S2P binding antibody assays for low doses $0.1 \mu \mathrm{g}$ and $0.25 \mu \mathrm{g}$ of mRNA-encoded S2P immunogen for serum collected 2 weeks after the boost. A Linear Regression Model analysis including LNP and dose as predictors showed that $\mathrm{C} 24$ binding antibody OD were significantly higher than MC3 ( $p=0.0005)$. Mean +/- SEM. b) ELISA optical density at the transitional dilution of 54,000 for S2P binding antibody assays for higher doses $0.5 \mu \mathrm{g}$ and $1.0 \mu \mathrm{g}$ of mRNA-encoded S2P immunogen for serum collected 2 weeks after the boost. A Linear Regression Model analyses including LNP and dose as predictors showed that $\mathrm{C} 24$ binding antibody OD were significantly higher than MC3 (p=0.01). Mean +/- SEM. c) C24 LNPs generated a detectable FRNT50 titer against VSVAG-RFP SARS-CoV-2 pseudovirus 3 weeks after a single Prime injection of a $1 \mu \mathrm{g}$ dose while MC3 LNPs did not (left Prime panel). Two weeks after the Boost (right Boost panel), C24 LNPs at 0.25 to $1 \mu \mathrm{g}$ dose revealed FRNT50 titers that were $\sim 10$ fold higher than MC3 LNPs at the same doses. A Linear Regression Model analysis of log-transformed FRNT50 titers including dose and LNP as predictors showed that C24 FRNT50 titers were significantly higher than MC3 for the Prime $(p=0.00002)$ and for the Boost $(p=0.011)$. Mean $+/-$ SEM. d) Neutralization of pseudovirus variants representing the variants D614G and ZA suggested FRNT50 titers were higher for C24 than the MC3 LNP, although statistical analyses did not find significant differences. Mean +/- SEM. 


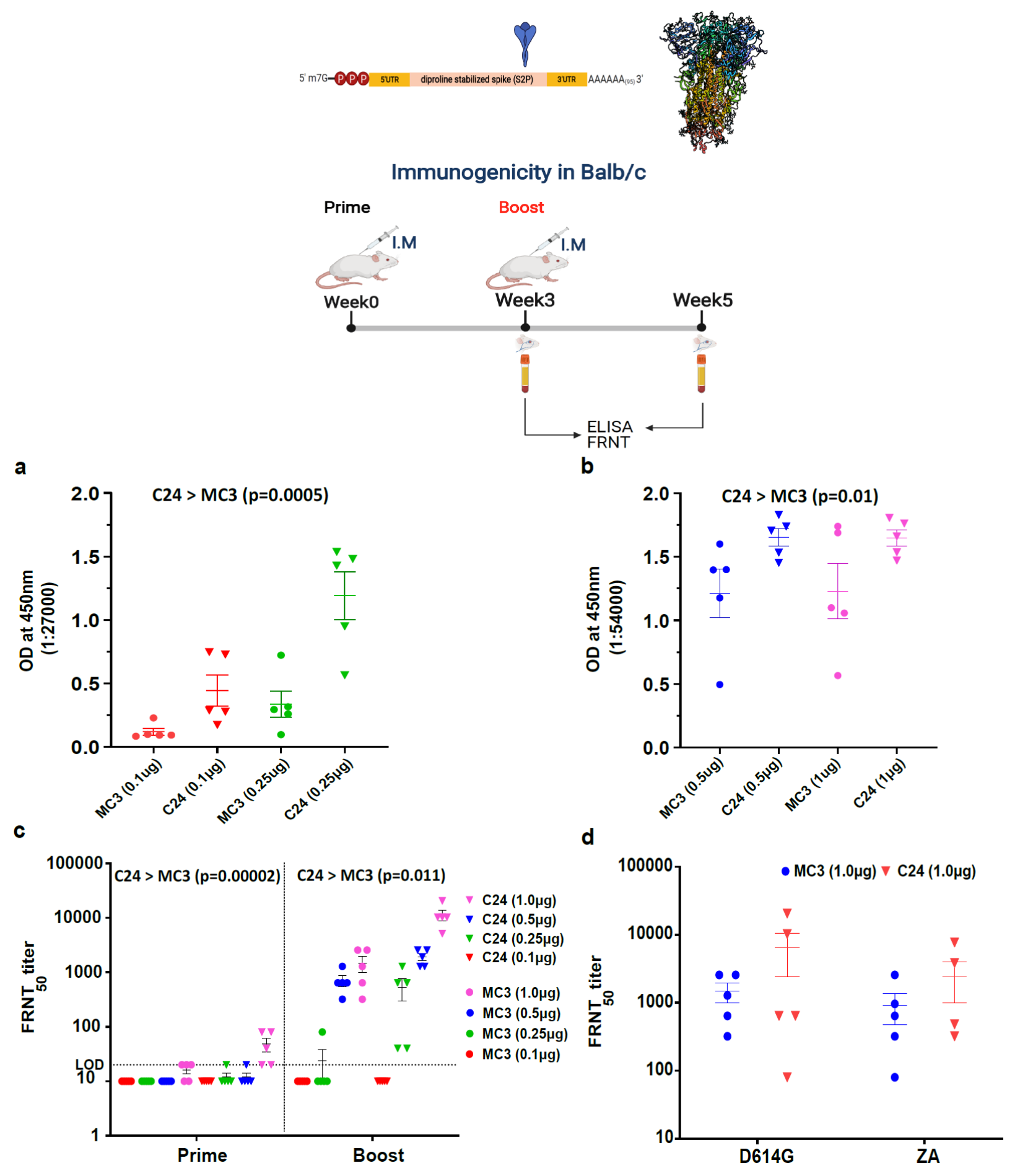


Figure 5. C24 LNPs are protective against lethal SARS-CoV-2 challenge at low doses of the S2P immunogen and completely eliminate lung infection. C24 LNPs containing $0.25 \mu \mathrm{g}$ of mRNA encoded S2P immunogen were entirely protective (a) against a lethal challenge of SARSCoV-2 while MC3 LNPs were protective at a higher $0.5 \mu \mathrm{g}$ dose (e) in the K18-hACE2 mouse $(\mathrm{N}=3$ per group from $\mathrm{N}=5$ at day zero since 2 animals per group were taken on day 5 to assess lung viral titers). One of 3 animals in the C24 group also survived at the very low dose of $0.1 \mu \mathrm{g}$. Statistical analyses did not show a significant difference with the small numbers of animals per dose $(n=3)$. Neutralization of SARS-CoV-2 in a plaque assay by PRNT ( $N=5$ per group) demonstrated C24 LNPs had neutralizing activity at $0.25 \mu \mathrm{g}$ dose (b) while MC3 only at $1 \mu \mathrm{g}$ dose (f) after the Prime. A Linear Mixed Effects Model analysis including LNP, dose and dilution as predictors showed that C24 significantly reduced \% Virus Detected more than MC3 $(p=0.021$ for b versus f). $\mathrm{C} 24$ had $100 \%$ neutralizing activity at $0.25 \mu \mathrm{g}$ dose after the Boost for the dilutions tested (c) while MC3 only at $1 \mu \mathrm{g}(\mathrm{g})$. A Linear Mixed Effects Model analysis including LNP, dose and dilution as predictors showed that C24 significantly reduced \% Virus Detected more than MC3 ( $<<0.00001$ for $\mathrm{c}$ ) versus $\mathrm{g}$ ). Assessment of lung viral titers at day 5 post infection in a plaque assay $(\mathrm{N}=2)$ found that $\mathrm{C} 24 \mathrm{LNPs}$ completely eliminated lung infection at a $0.5 \mu \mathrm{g}$ dose (d) while MC3 LNPs were not able to entirely eliminate lung infection even at the highest $1 \mu \mathrm{g}$ dose tested (h). A Linear Regression Model analyses of log transformed Viral Titers including LNP and dose as predictors showed that C24 significantly reduced Lung Viral Titers more than MC3 $(p=0.00008)$. SEM is shown for one dose only for clarity in $b, c, f, g$. Weight and temperature recordings post-challenge are in Supplementary Figure 3. Mean +/- SEM. 


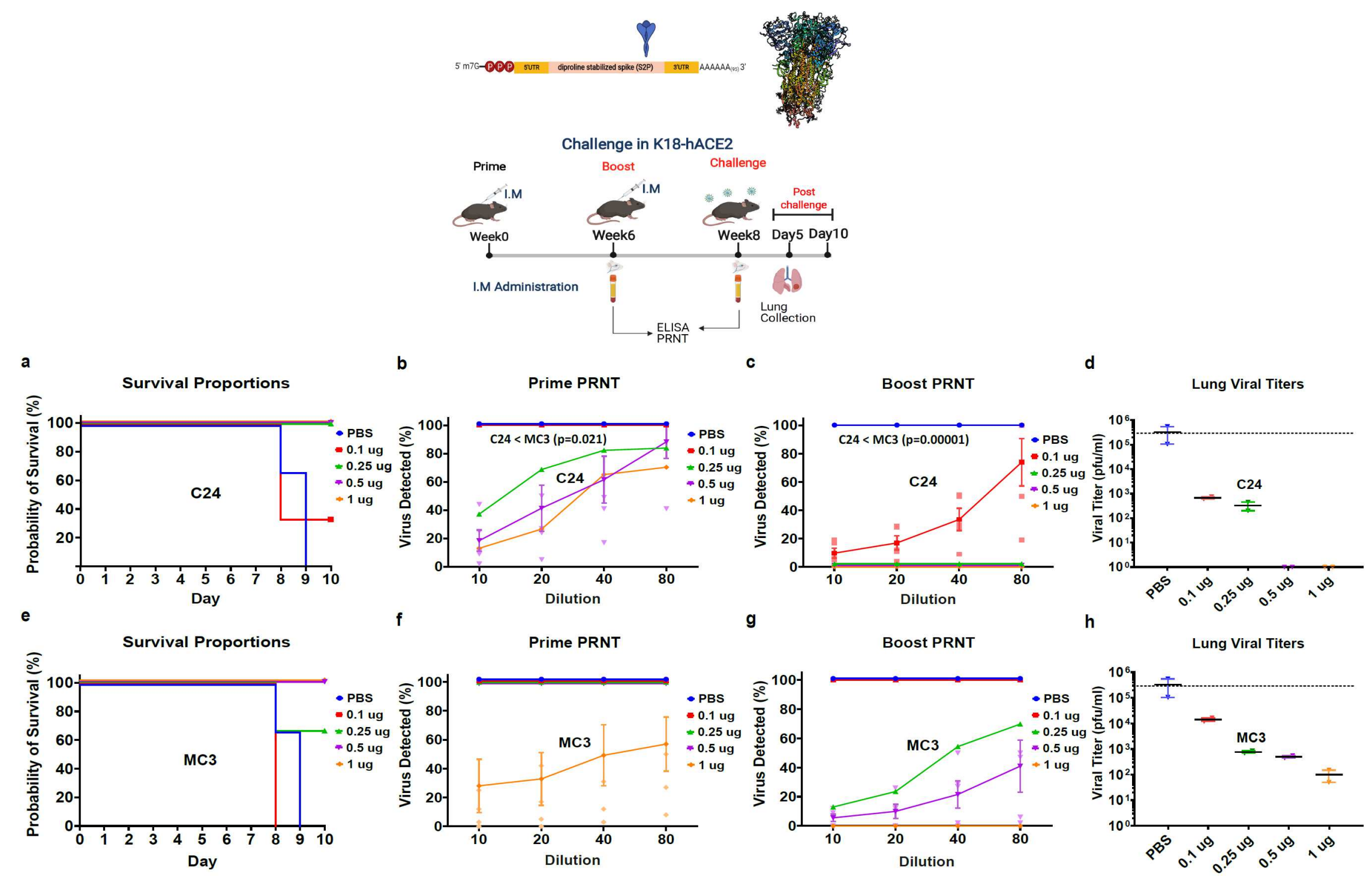


Figure 6. Local injection site inflammation is lower for C24 than MC3 mRNA LNPs. C24 LNPs (a-c) elicited less inflammation at the injection site than MC3 LNPs (d-i) 24 hours after injection that was consistent with lower levels of macroscopically observed swelling of C24 than MC3, assessed visually and by manual palpation. The $50 \mu 1$ injection into the medial gastrocnemius (MG) containing $5 \mu \mathrm{g}$ of mRNA and $\sim 65 \mu \mathrm{g}$ total lipids was mainly found at the injection site (IS) between the medial gastrocnemius and lateral gastrocnemius (LG) in a, $\mathrm{d}$ and $\mathrm{g}$. The lipid was difficult to distinguish from local adipose tissue. MC3 elicited a strong inflammatory response throughout the leg inducing macroscopically evident swelling and histologically observed inflammation of the synovial tissue (e, f) that was absent in C24 injected legs (b, c). The inflammatory response at the injection site involved infiltration of neutrophils and blood vessels (h) and generated mixed cell-type lymphoid structures (i) at the injection site that were not observed in non-injected controls. These responses are representative of a group of 3 animals for each of MC3 and C24. Staining is hematoxylin and eosin. 


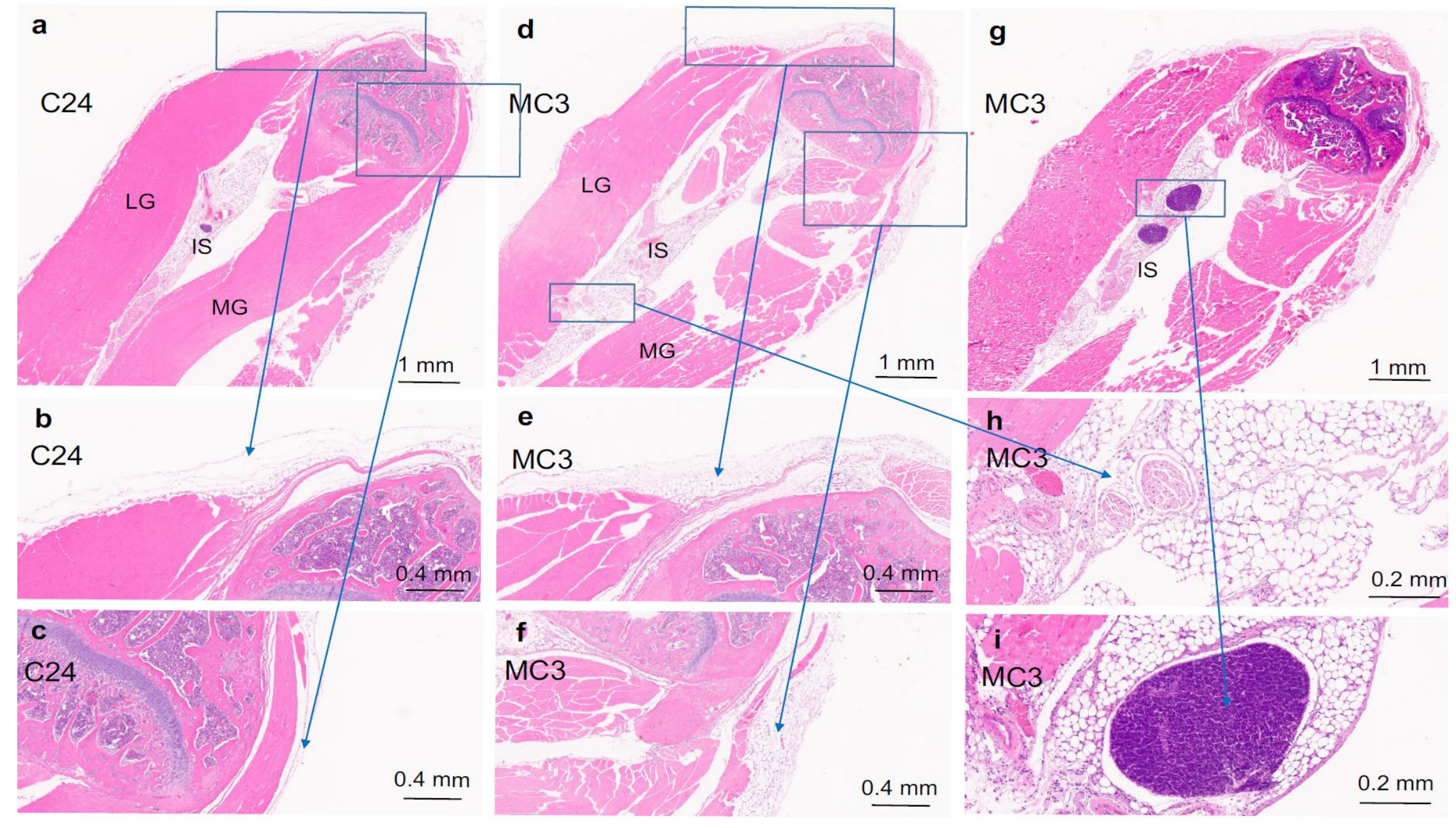


Figure 7. Bioactivity and mRNA integrity of C24 and MC3 LNPs are stable at $4^{\circ} \mathrm{C}$ but decline at higher temperatures over 2 weeks. a) Bioactivity was measured at Day 0, 2, 4, 7 and 14 by luciferase expression in HEK 293 cells at $25 \mathrm{ng}$ per well containing 12,000 cells. Bioactivity was stable for both C24 and MC3 LNPs stored in PBS at $4{ }^{\circ} \mathrm{C}$ but declined by $\sim 20-40 \%$ when stored at room temperature (RT) over a 2-week period. b) There was no detectable change in LNP size by DLS nor in \% mRNA inaccessible to Ribogreen (c). d) Theoretical calculation of mRNA integrity (\% uncleaved) using the model in equation "e" of Li and Breaker 1999 suggests free FLuc mRNA half-lives at $\mathrm{pH} 7.4$ of 2,300 days at $4^{\circ} \mathrm{C}, 125$ days at $\mathrm{RT}$ and 11 days at $37^{\circ} \mathrm{C}$. e) mRNA was extracted from LNPs using chloroform/methanol just after being produced on day 0 as well as after 19 days of storage in $\mathrm{PBS}$ at $4^{\circ} \mathrm{C}$, RT and $37^{\circ} \mathrm{C}$ and analyzed by microfluidic electrophoresis. No detectable degradation was found after 19 days at $4^{\circ} \mathrm{C}$ (compared to day 0 ) while storage at higher temperatures (RT and $37^{\circ} \mathrm{C}$ ) produced increasing amounts of mRNA cleavage that was qualitatively consistent with higher degradation at higher temperature predicted by the model in (d). The least degraded example of the 3 LNPs measured for each condition is shown in (e). The peak below 20s is a standard while the peak near 40s above the main mRNA Fluc peak is the product of an untemplated extension that is not amenable to elimination using the cellulose method used to purify the mRNA ${ }^{45}$. mRNA integrity was estimated by the area under the curve (AUC) corresponding to the FLuc mRNA peak and was normalized to the average day 0 value for C24 and MC3 LNPs taken together. f) mRNA integrity was stable for at least 19 days at $4{ }^{\circ} \mathrm{C}$ and declined at higher temperatures but less so for $\mathrm{C} 24$ than for $\mathrm{MC} 3$. $\mathrm{N}=3$ or for some $\mathrm{N}=2$ due to technical irregularities in the trace of some samples that precluded quantification. 

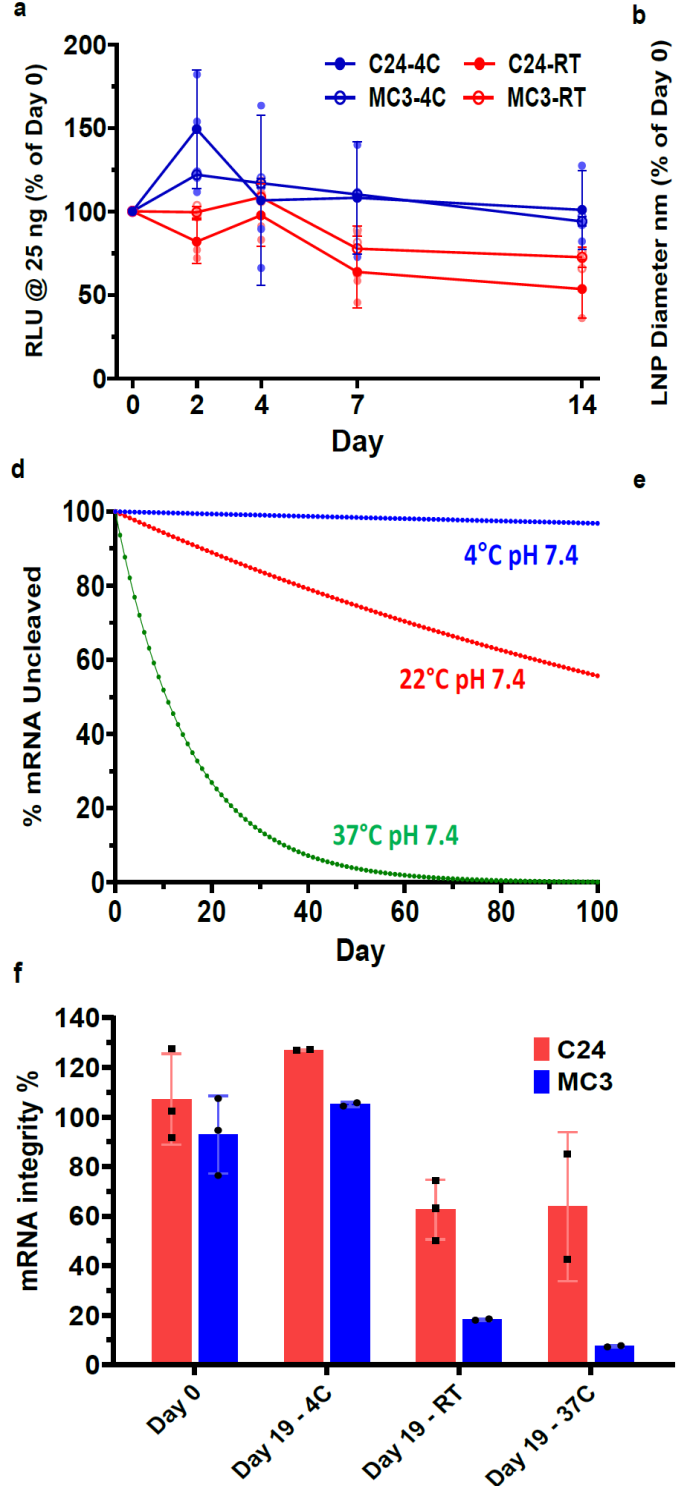
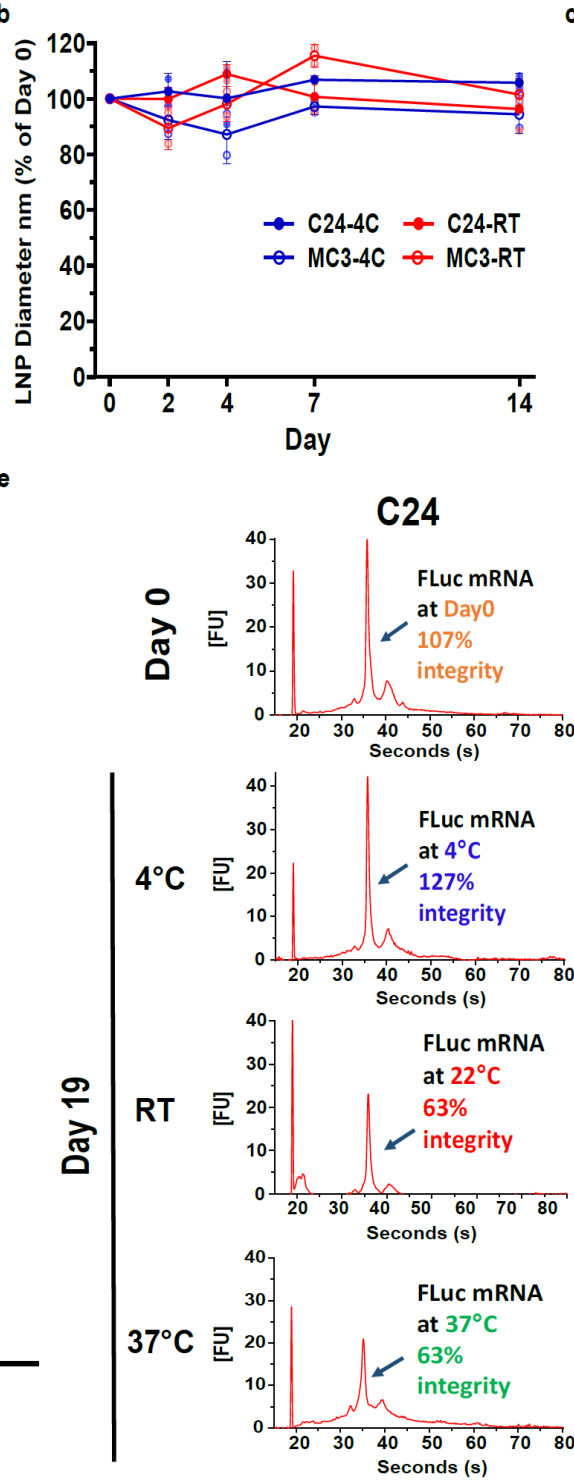

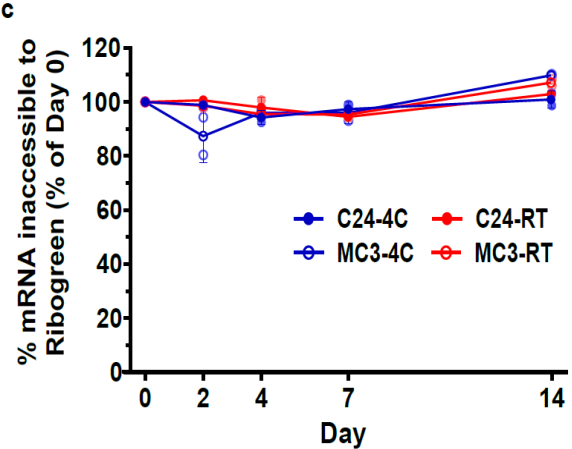

MC3
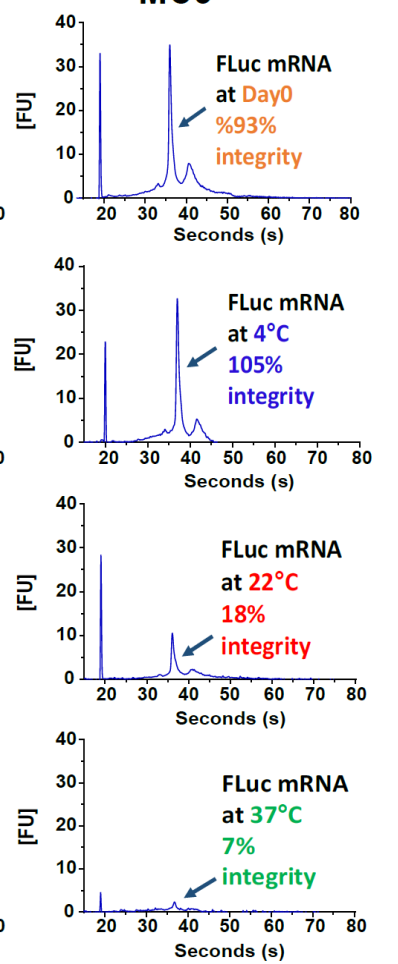


\section{Supplementary Information}

Supplementary Figure 1. ${ }^{1}$ H NMR, C13 and DEPT NMR spectra for synthesized compounds.
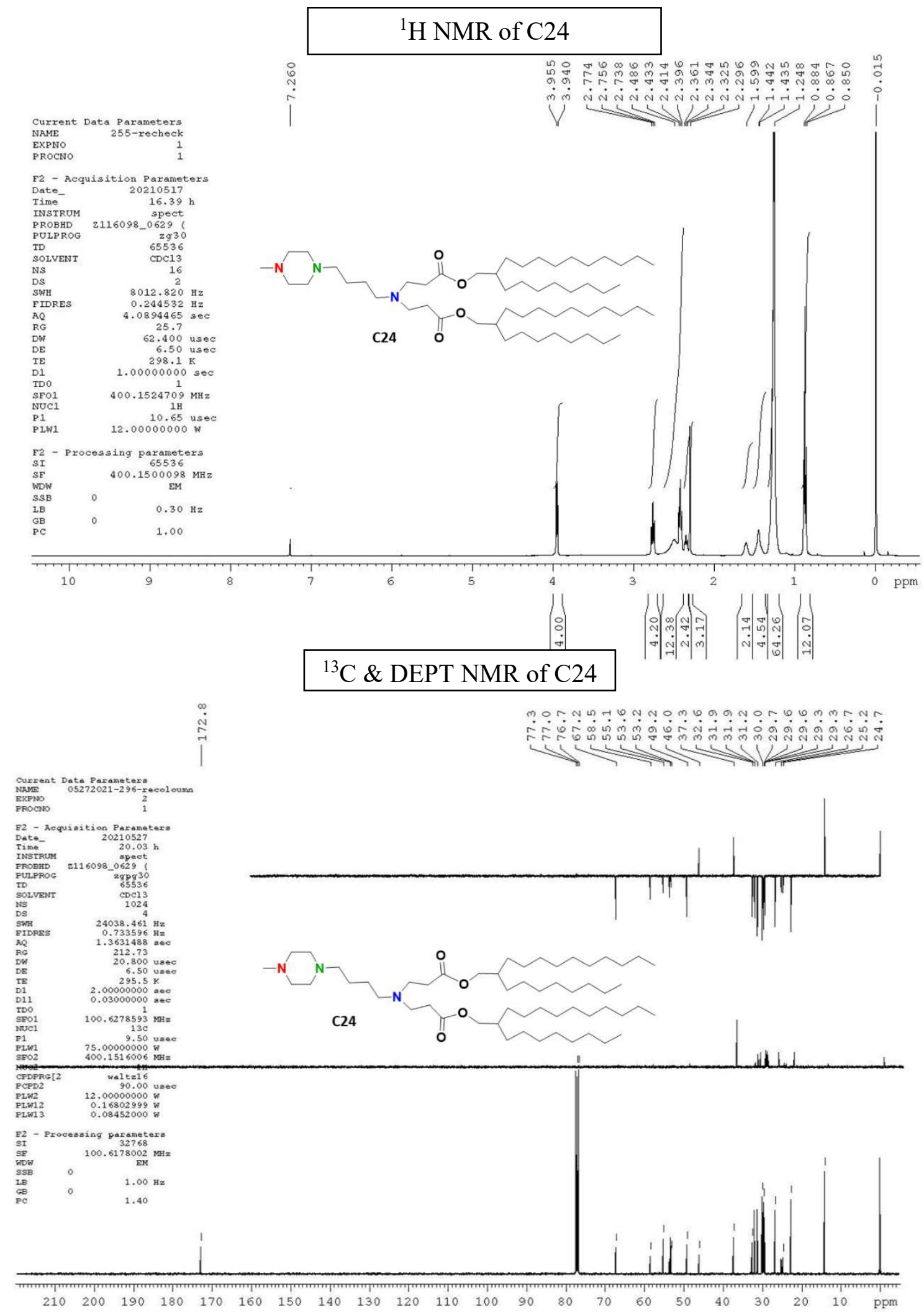


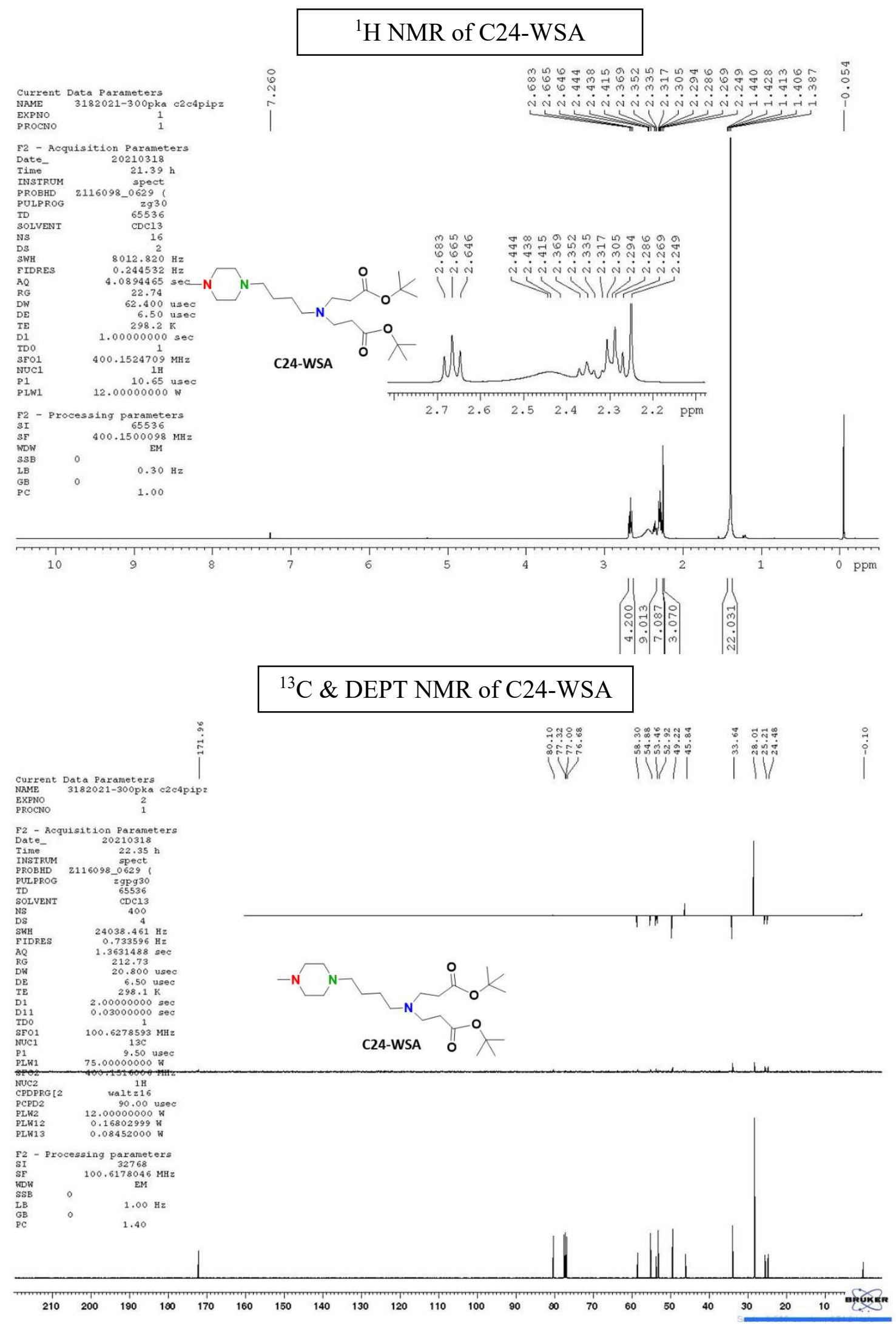




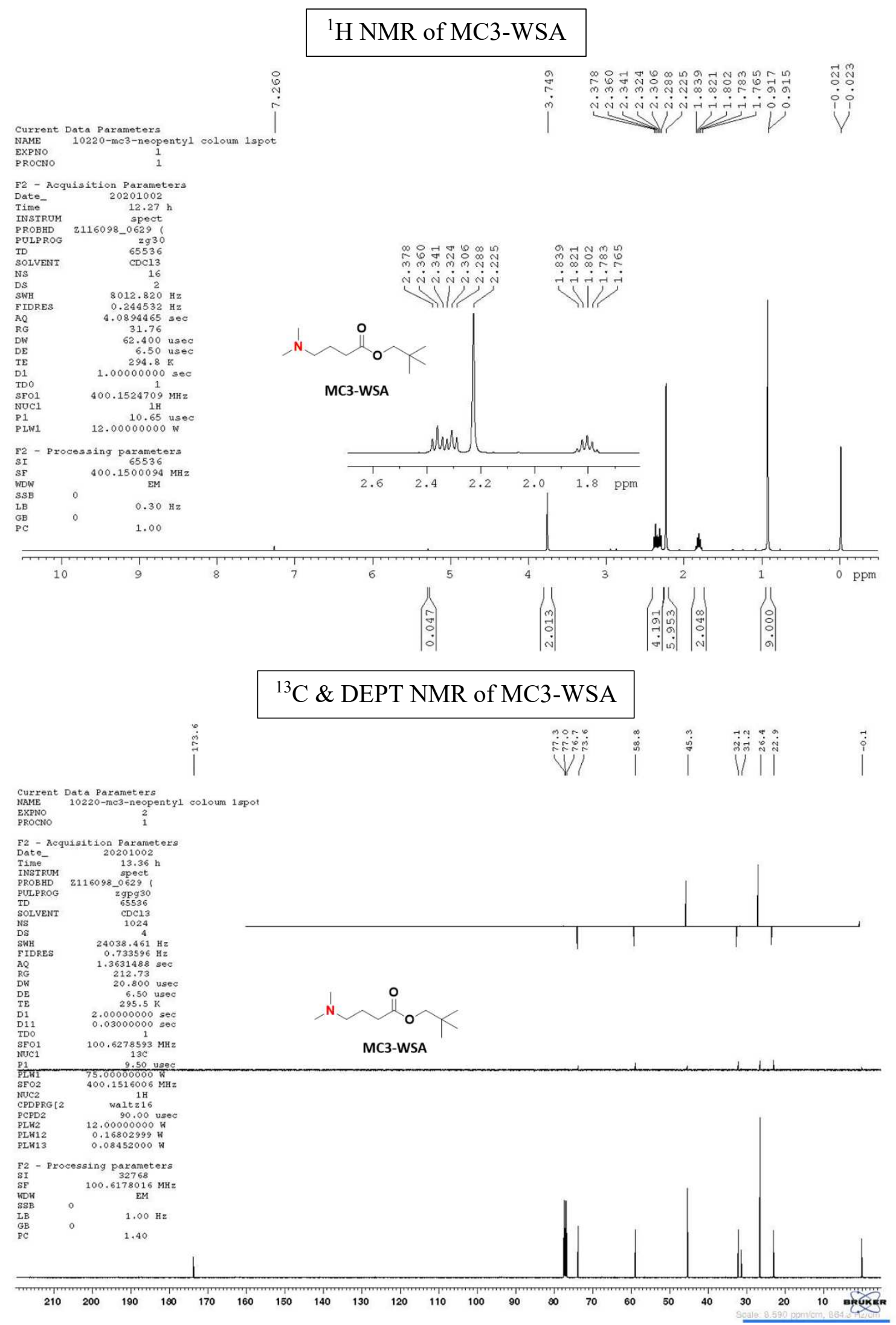


Supplementary Figure 2a. 1H NMR stacked spectra of N1 protons (red) and N3 protons (blue) of the C24 water soluble analogue (C24-WSA) at different pH values used to determine pKa shown in Figure $1 \mathrm{~b}$.

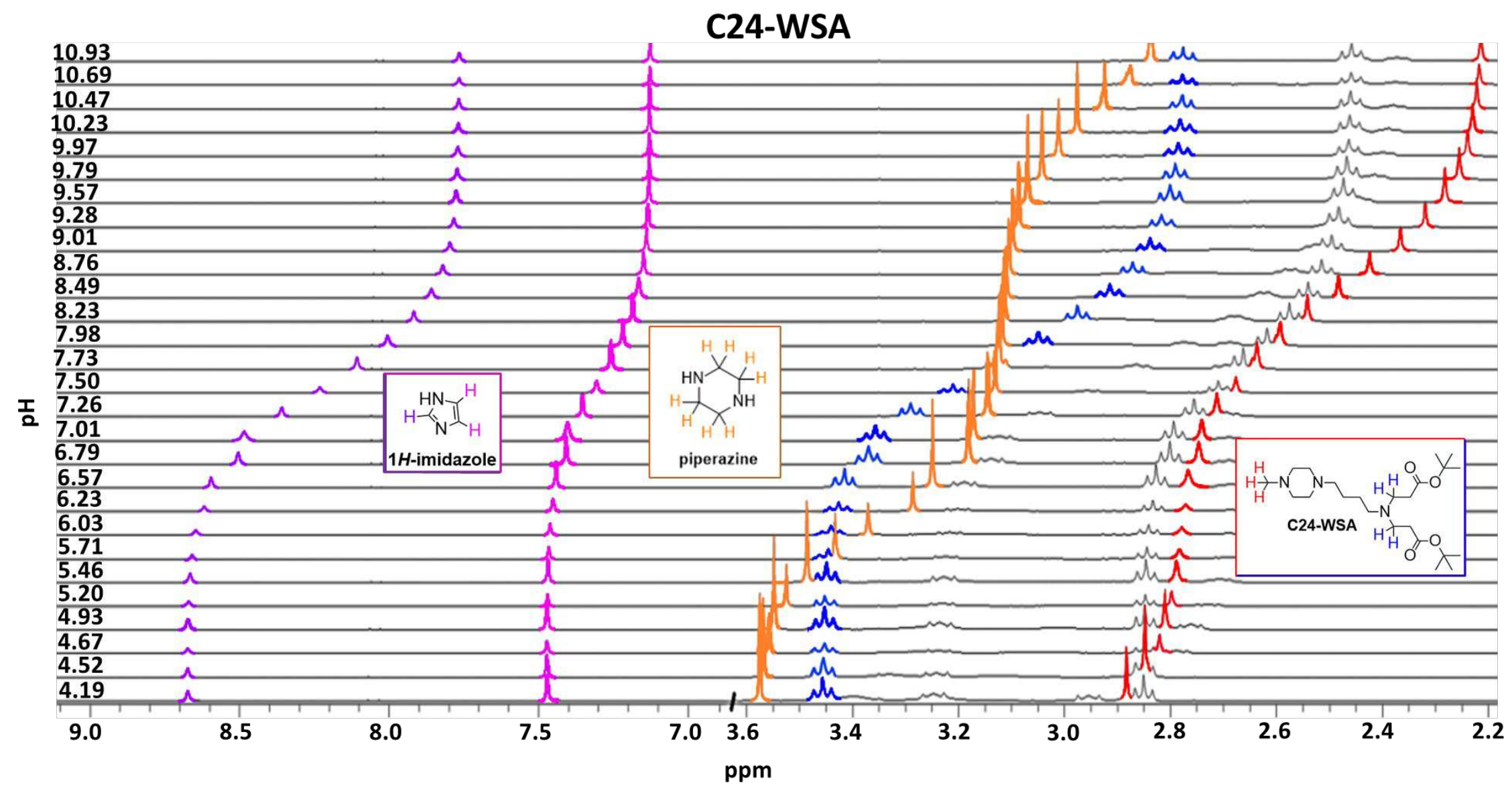


Supplementary Figure 2b. 1H NMR stacked spectra of N2 piperazine (green) of the C24 water soluble analogue (C24-WSA) at different pH values used to determine pKa shown in Figure 1 b.

\section{C24-WSA}

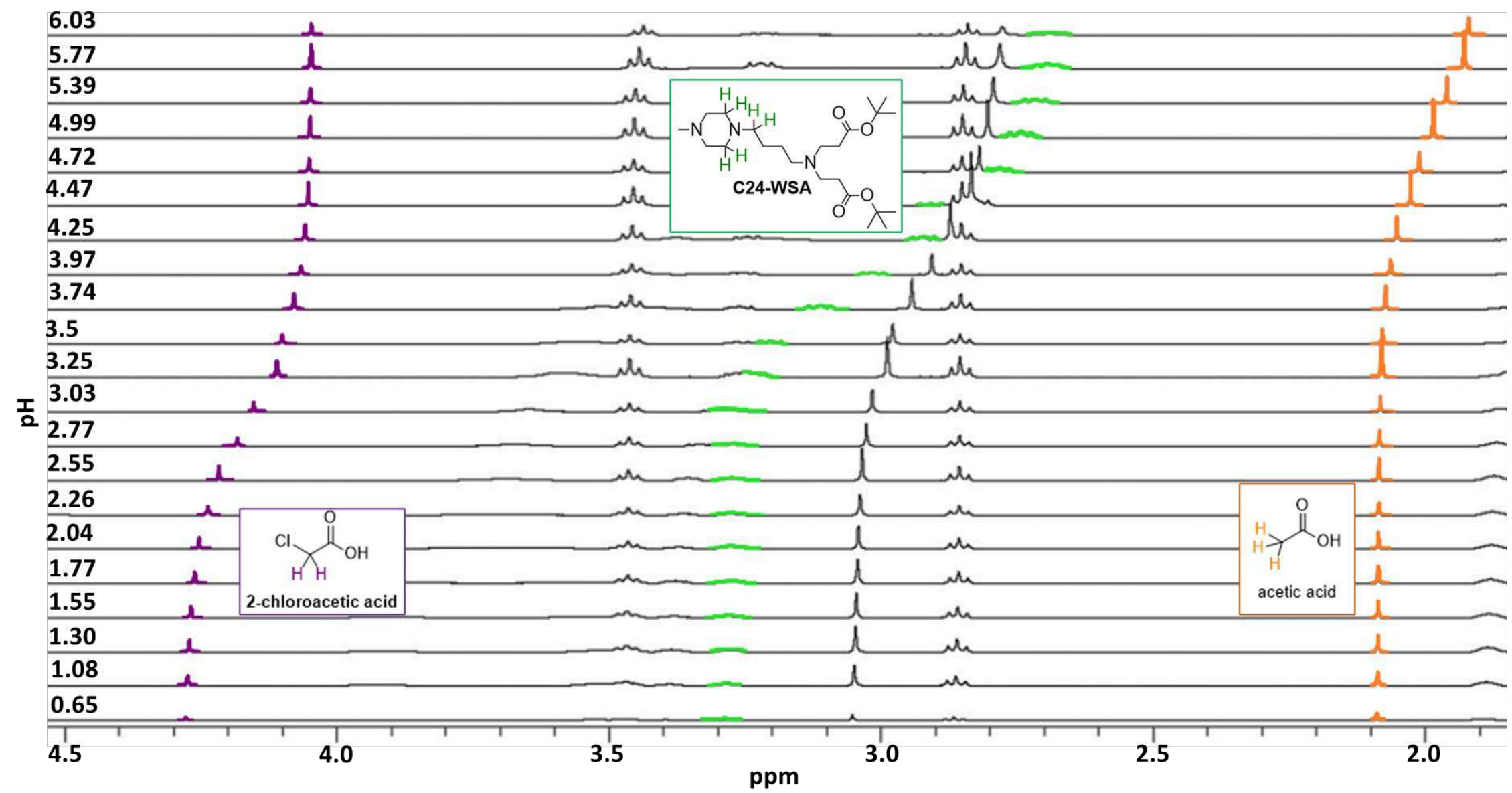


Supplementary Figure 2c. 1H NMR stacked spectra of terminal dimethylamine protons of the MC3 water soluble analogue (MC3-WSA) at different pH values used to determine pKa shown in Figure 1c.

\section{MC3-WSA}

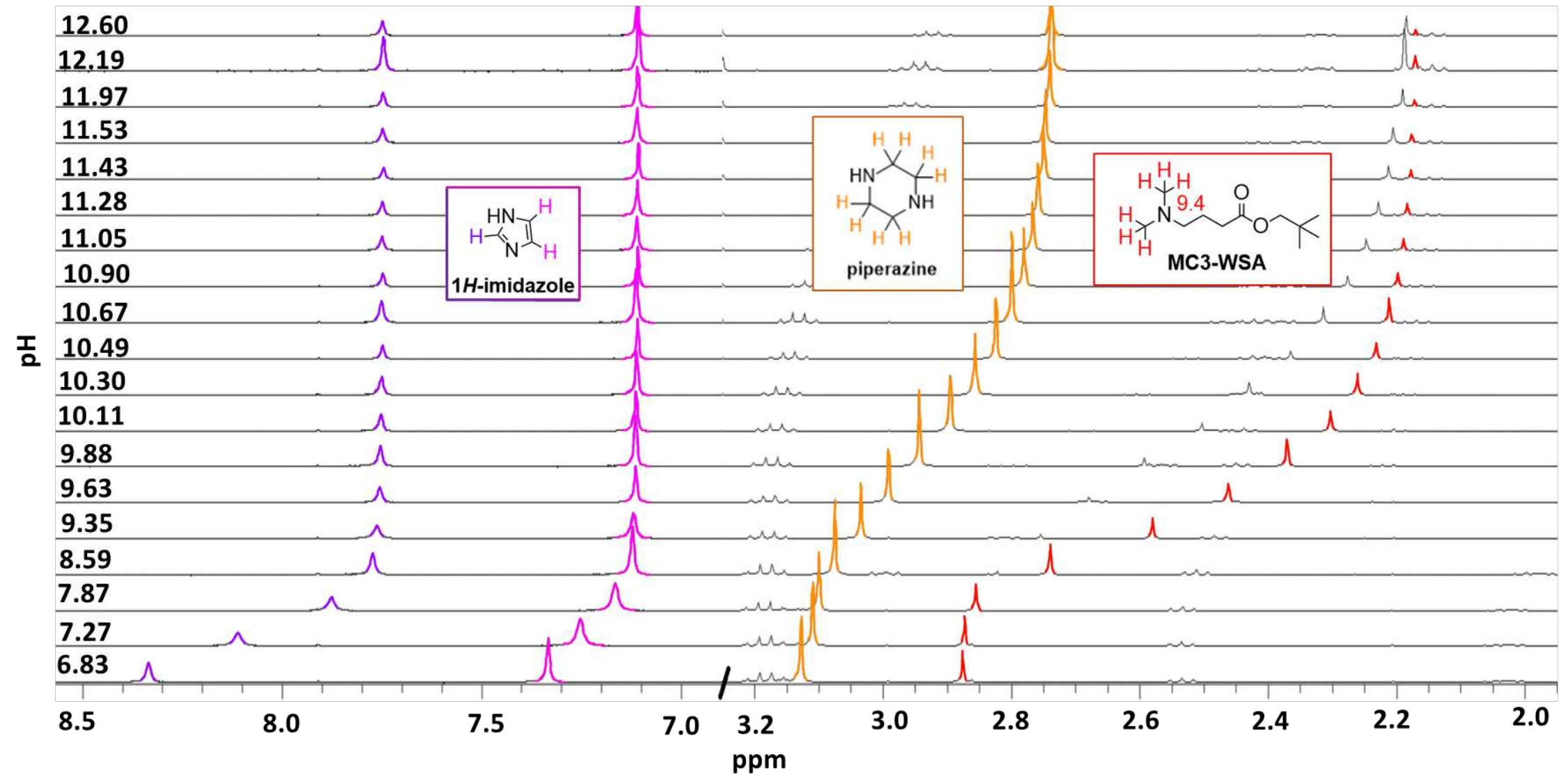


Supplementary Figure 3. Weight and Temperature recordings of K18-hACE2 mice subject to lethal challenge on Day 0 after a Prime-Boost vaccination with C24 and MC3 LNPs containing the mRNA-encoded S2P immunogen at doses ranging from 0.1 to $1.0 \mu \mathrm{g}$.

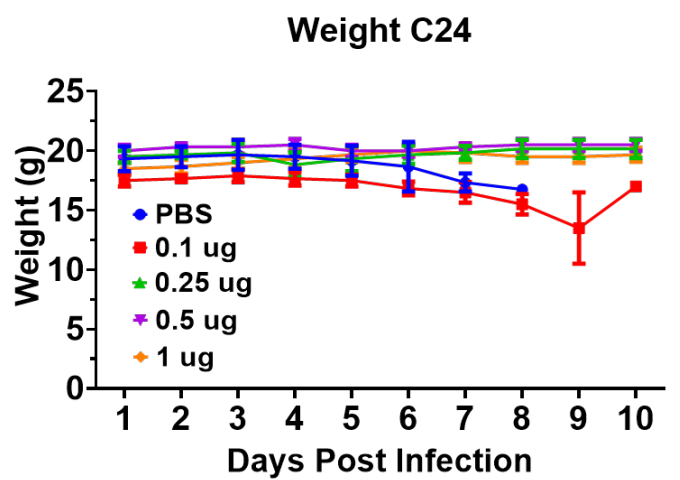

Weight MC3

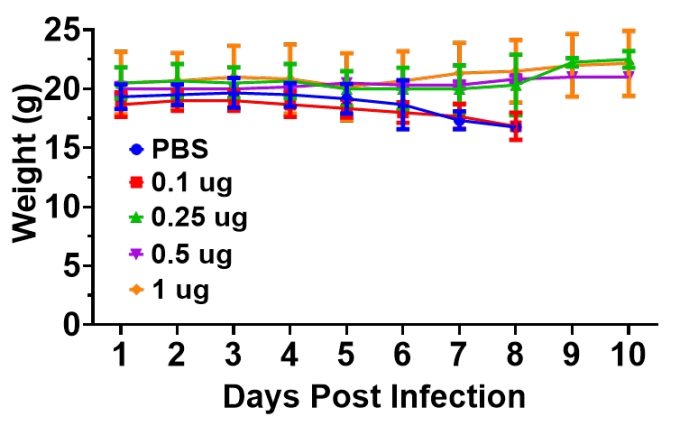

Temperature C24

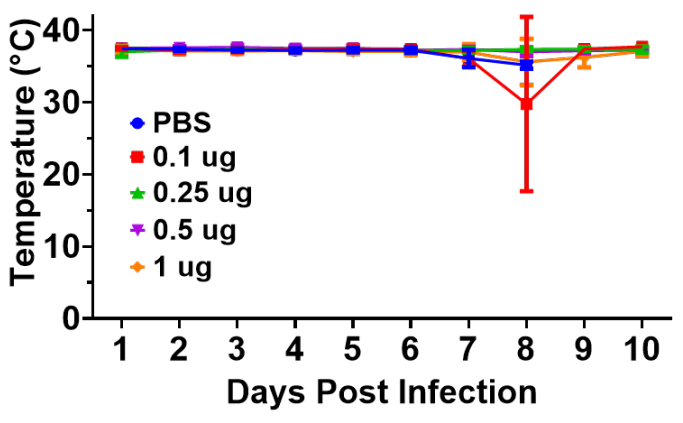

Temperature MC3

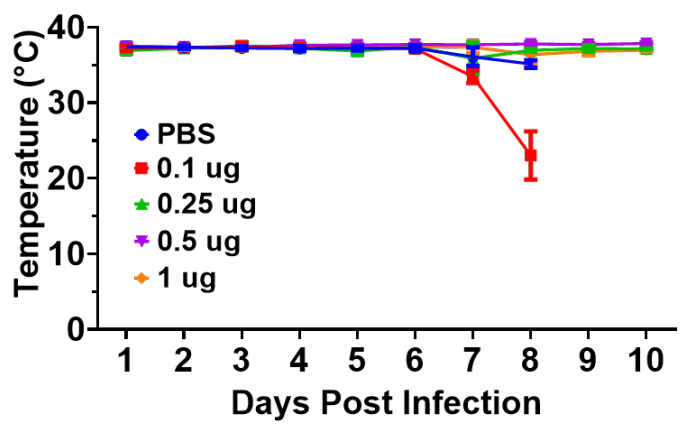

